\title{
Interannual variability of seasonal rainfall in Cordoba, Argentina, evaluated from ENSO and ENSO Modoki signals and verified with MODIS NDVI data
}

\author{
Antonio C. de la Casa ${ }^{1}$ D . Gustavo G. Ovando ${ }^{1}$. Guillermo J. Díaz ${ }^{1}$
}

Received: 24 June 2019 / Accepted: 7 November 2019 / Published online: 16 November 2019

C) Springer Nature Switzerland AG 2019

\begin{abstract}
El Niño-Southern Oscillation (ENSO) is an atmospheric and oceanic signal closely linked with the short-term (interannual) climate variability and, as part of the global atmospheric circulation, influences for several months the weather in different regions of the world. As a proxy of ENSO, the Southern Oscillation Index (SOI) has shown a moderate ability to predict rainfall behavior on the territory of Córdoba province, Argentina. Several studies last years have postulated for the existence of the El Niño Modoki, "a similar but different" type of El Niño, with an increasing interest in determining the characteristics of its evolution and the impact of associated teleconnections over the weather around the world. Moreover, spectral indicators such as the normalized difference vegetation index (NDVI) have also been used to monitor the ENSO cycle. The influence in a predictive way of both ENSO and ENSO Modoki over seasonal rainfall indicators: amount (PP), frequency (DPP) and maximum daily precipitation (PPmax), was analyzed during the period from 1960 to 2017 in Córdoba Province, Argentina. Complementarily, the ENSO influence on vegetation behavior was also assessed during the rainfall season by using NDVI data from MODIS-TERRA for the period 2000-2017 to verify the predictive potential of the climate signal. Before the beginning of the rainy season, the August and September SOI average $\left(\mathrm{SOI}_{\mathrm{as}}\right)$ shows negative linear relationships with the rainfall attributes in almost all the territory of Córdoba that, although significant in statistical terms, are relatively weak. El Niño Modoki Index (EMI) used to represent the ENSO Modoki did not improve predictions on the rainfall behavior in Córdoba compared to SOI. Although the ENSO $\left(\mathrm{SOI}_{\mathrm{as}}\right)$ explains a little portion of interannual variability on subsequent seasonal rainfall, just between 14 and 22\% for the entire region, when ENSO phases' fluctuations upon NDVI data were analyzed, a very similar scheme was established. It is important to realize these responses show a strong local dependence associated with the environment resources and agricultural scheme own of each place. These results validate the use of the ENSO as a warning signal to anticipate the productive risk of the region, particularly when the Neutral years are discarded.
\end{abstract}

Keywords Southern Oscillation Index · El Niño Modoki Index · Seasonal rainfall anomaly · Vegetation anomaly Climate risk

\begin{tabular}{llll}
\multicolumn{2}{l}{ Abbreviations } & DPP & Rainfall frequency or rainy days \\
ENSO & El Niño-Southern Oscillation & PPmax & Maximum daily precipitation \\
SOI & Southern Oscillation Index & MODIS & $\begin{array}{l}\text { Moderate-Resolution Imaging } \\
\text { SOI }\end{array}$ \\
NDVI & August and September SOl average & & Spectroradiometer \\
PP & Normalized difference vegetation index & TERRA & Terra (EOS AM) satellite \\
& Rainfall amount & EMI & El Niño Modoki Index
\end{tabular}

Antonio C. de la Casa, delacasa@agro.unc.edu.ar | ${ }^{1}$ Facultad de Ciencias Agropecuarias, Universidad Nacional de Córdoba, Ing. Agr. Félix Aldo Marrone 746 - Ciudad Universitaria, 5000 Córdoba, Argentina. 


\begin{tabular}{|c|c|}
\hline NOA & North Atlantic Oscillation \\
\hline SST & Sea surface temperature \\
\hline SSTA & Sea surface temperature anomaly \\
\hline MEI & Multivariate ENSO Index \\
\hline ONI & Oceanic El Niño Index \\
\hline PDO & Pacific Decadal Oscillation \\
\hline $\mathrm{NOI}$ & North Oscillation Index \\
\hline SMN & $\begin{array}{l}\text { Servicio Meteorológico Nacional (República } \\
\text { Argentina) }\end{array}$ \\
\hline $\mathrm{Cl}$ & Confidence interval \\
\hline $\mathrm{Cl}_{1}$ & Lower limit of $\mathrm{Cl}$ \\
\hline $\mathrm{Cl}_{\mathrm{u}}$ & Upper limit of $\mathrm{Cl}$ \\
\hline$A X_{\text {period }}$ & Rainfall anomaly for a time period \\
\hline $\mathrm{AND}_{\text {period }}$ & NDVI anomaly for a time period \\
\hline$T$ & The linear trend about time of a variable \\
\hline MOD13Q1 & MODIS-Terra product \\
\hline MCV & Maximum composite value \\
\hline BO & Córdoba Observatorio \\
\hline PB & Pajas Blancas Aero \\
\hline LB & Laboulaye Aero \\
\hline MJ & Marcos Juárez Aero \\
\hline PI & Pilar Observatorio \\
\hline $\mathrm{RC}$ & Río Cuarto Aero \\
\hline VM & Villa de María de Río Seco \\
\hline VD & Villa Dolores Aero \\
\hline DMI & Dipole Mode Index \\
\hline IOD & Indian Ocean Dipole \\
\hline
\end{tabular}

\section{Introduction}

The atmospheric properties in each region of the world present a wide spectrum of variability including, from the ever-changing weather conditions, with a rapid transition over the course of hours and days, to the climate states evolution whose variation over time is analyzed considering either progressive trends $[28,70]$, periodic fluctuations $[57,61]$, or a climatic jump $[33,47]$. In this sense, usually the rainfall time series variability is analyzed by decomposing on three timescales of short, medium and long term [26]. While the long-term variability refers to climate change, with a temporal dimension that must necessarily extend for several years, short-term variability happens from a few days to weeks, months and also including the interannual variability. In spite of the fact that it explains most of the rainfall variability, the predictive models usually assign the interannual variability a residual character [26]. Knowing the dynamics of rainfall fluctuations in a region is very important to anticipate the impact of environmental adversities and mitigate the major agricultural production climate risks, such as drought and water surplus [44].
Related to the long-term change, the climate of Córdoba Province between 1940 and 2010 presents a more humid condition today as a result of increased precipitation [20], which has a strong impact over agricultural potential of the region [19]. Also, time series of rainfall in the central region of Argentina present a medium-term modulation that has been assessed by using different methods. Lucero and Rozas [45] analyzed non-periodic fluctuations in the time series of rainfall using a wavelet function and determined that fluctuations with a timescale of about 10 and 20 years construct the growing trend of annual rainfall of Cordoba. Following the nonlinear method of $[13,61]$ also shows that rainfall series in the central region of Argentina have a trend change or breaking points each $10-20$ years. Furthermore, as rainfall has a direct impact on water resources of a territory, the central region of Argentina shows fluctuations both in excess and in deficiency of water with the same recurrence [16].

Among the short-term cycles reported frequently in climate studies, the quasi-biennial oscillation of equatorial stratospheric winds is one of the best known. Meanwhile, the interannual dynamics of the North Atlantic Oscillation (NOA) has also quasiperiodicities of approximately 2.2 years [46]. However, the climate fluctuation most studied at this timescale probably is El Niño-Southern Oscillation (ENSO), which is recognized as the principal large-scale climatic forcing of year-to-year precipitation variability in the Indo-Pacific region [44] and Australia [8, 64], among others. While the mechanism that determines the periodic behavior of the ENSO has no definitive explanation yet, it is an interaction phenomenon between the atmosphere and ocean and it strongly impacts short-term rainfall variability $[9,26]$. The ENSO events have irregular intervals of about 2-7 years, and, as the phenomenon modifies the global atmospheric circulation, during several months the weather is affected in different regions of the world [10, 35, 39], although its impact is more noticeable in tropical regions [11].

The ENSO phenomenon with anomalies in the sea surface temperature (SST) and the associated variations of atmospheric pressure in the equatorial Pacific Ocean region, through the so-called atmospheric teleconnections [62], influence the weather conditions at seasonal scale in different regions of the world [52,54], including Argentina [10,55]. In Córdoba Province, the ENSO impact on rainfall produces equal or above normal values during the warm phase (El Niño) and the opposite effect during the cold phase (La Niña) which is directly associated with droughts occurrence of different duration and intensity. Indeed, negative rainfall anomalies in La Niña years explain a higher frequency of negative maize yield anomalies in the region of Córdoba [17]. With predictive purposes, various ENSO indicators such as the Multivariate ENSO Index 
(MEI), the Southern Oscillation Index (SOI) and the Oceanic El Niño Index (ONI), as well as other climate indicators such as the Pacific Decadal Oscillation (PDO) and North Oscillation Index (NOI), have shown a moderate ability to predict the occurrence of rainfall in the warm semester at the territory of Córdoba Province [14]. In addition, the period between May and September is when these indicators are more linked to the occurrence of seasonal rain later [14].

Recently, two different types of El Niño events have been proposed $[2,34,40,63]$. While El Niño is traditionally recognized as a warming of the sea surface in the easternto-central equatorial Pacific Ocean, the other El Niño event with the warming confined to the international dateline region can also occur. This type of El Niño has been called with different names: Central Pacific El Niño [34], dateline El Niño [40], or warm pool El Niño [38]. In this paper, the name El Niño Modoki was used, that means "something similar but different." The global teleconnections of ENSO Modoki are also different from that of typical ENSO, and the evidence suggests they have been more frequent and persistent in the last decades [2]. They are opposite to one another, or weaker/stronger or asymmetric, depending on the region and the season of teleconnection [51]. Therefore, there is a growing interest to assess its influence on each particular territory.

While a thorough knowledge of rainfall variability is still far from being reached, the predictability of short-term component based on their relationship with atmospheric and oceanic state of the equatorial Pacific offers some concrete possibility to reduce the level of risk and uncertainty in agricultural production. As strategic information, this knowledge can be used to establish in advance the most appropriate agricultural or environmental management guidelines according to each likely climate scenario [24]. Also, climate indices like SOI, PDO, MEl, etc., are useful to develop models for rainfall forecasting, as Abbot and Marohasy [1] have shown for Queensland, Australia, by using artificial neural networks.

The normalized difference vegetation index (NDVI) is a spectral indicator widely used to represent the presence, vigor and productivity of vegetation in a region [48]. Its use in remote sensing has allowed to identify and quantify the different types of vegetation present in a territory [22, 25], classify the cropped areas with different species [6], as well as to assess the impact of drought in various regions of the world [30,37] and Argentina [59]. As a proxy of vegetation, spectral indicators like NDVI have also been useful to monitor the ENSO cycle $[23,41,43,58,66]$.

The interannual variability of the quantity, frequency and intensity of precipitation is closely linked to the dynamics of the ENSO phases in the central region of Argentina. After establishing the relationship between the ENSO and seasonal rainfall in advance, and considering the major influence of water on the state and productivity of vegetation in a climate between subhumid and semiarid, the spectral data of NDVI have potential to confirm the effective range of the ENSO signal over this territory.

Even though the characteristic modes of ENSO influence over rainfall in the central region of Argentina are partially known, the particular objectives of this work were to validate the predictive capacity of this atmospheric-oceanic fluctuation in advance of rainfall start on more specific rainfall attributes, related not only to total quantity, but also to the frequency of events and their intensity. Then, looking for improving the predictive capacity of traditional ENSO over precipitation, the relationship between ENSO Modoki and rainfall variability was also explored, as well as the most opportune time of the year to establish a reliable predictor. As a proxy of vegetation, spectral NDVI data were also used to assess alternatively the effective range of the ENSO signal, to verify the predictive potential of this information from a more holistic perspective. In the Materials and Methods section, the data and their corresponding calculation are presented. This was structured into four parts: (1) rainfall indexes, (2) the Southern Oscillation Index (SOI), (3) the Enso Modoki Index (EMI), used to assess the state of ENSO, and finally (4) the normalized difference vegetation index (NDVI) to assess the condition of vegetation. Then, in the Results and Discussion section the following subjects are evaluated: (1) the ENSO and ENSO MODOKI influence on rainfall regime, (2) the ENSO influence on seasonal rainfall using $\mathrm{SOI}$ as a proxy and (3) the ENSO influence on vegetation using NDVI as a proxy.

\section{Materials and methods}

\subsection{Rainfall data}

The rainfall records analyzed in this study were obtained from the network of surface meteorological stations operated by the Servicio Meteorológico Nacional (SMN) in the province of Cordoba, Argentina. Figure 1 shows a map with the geographical location of these stations in the region.

The influence of both ENSO and ENSO Modoki on the rainfall regime of Córdoba was evaluated from daily rainfall data of the period 1960-2017 that were added, according to the seasonality of rainfall in the region, for the trimester October-November-December (indicated with the ond extension) and for all the warm semester from October to March (indicated by the ondjfm extension). In addition to the warm semester, cumulative rainfall values were also considered between October and April (Oct-Apr), October and May (Oct-May), November and April (Nov-Apr) and November and May (Nov-May), to assess more extensively 


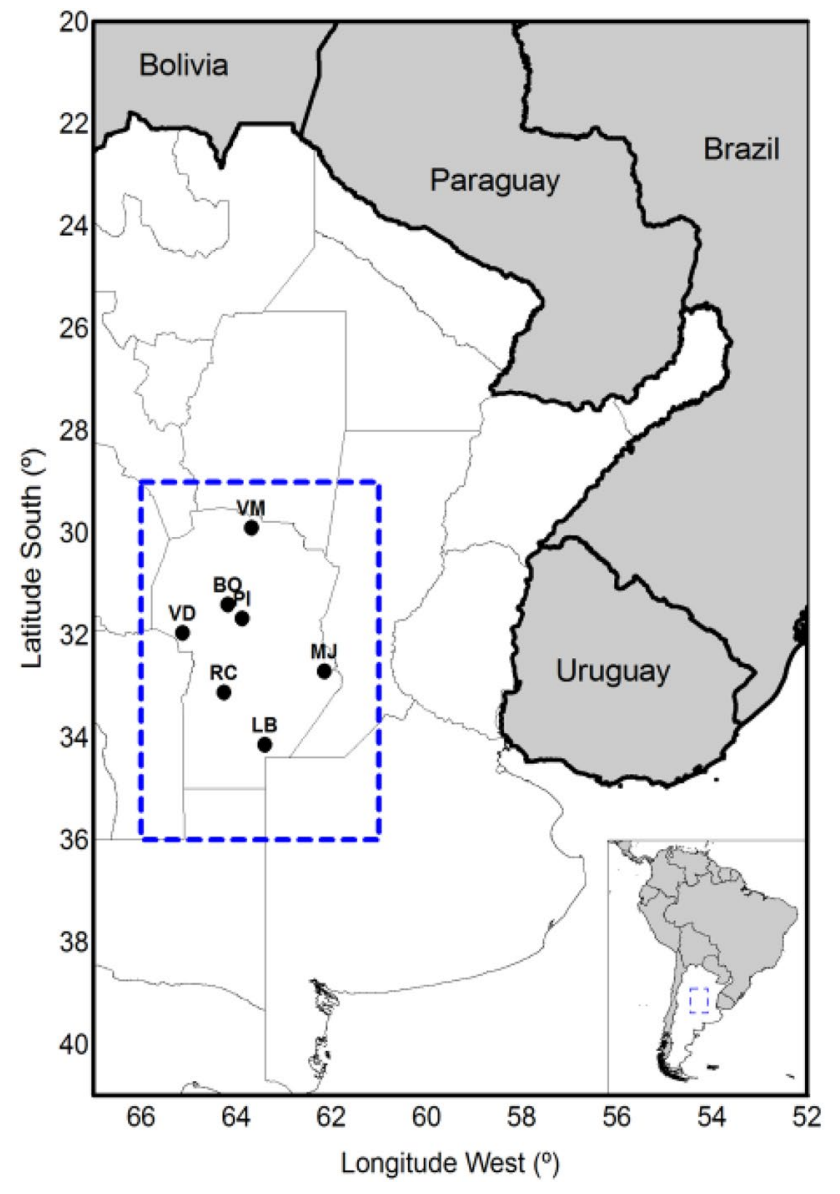

Fig. 1 Geographical location of the weather stations in the province of Córdoba, Argentina, whose meteorological data were used in this study: Córdoba Observatorio (BO); Laboulaye Aero (LB); Marcos Juárez Aero (MJ); Pilar Observatorio (PI); Río Cuarto Aero (RC); Villa de María de Río Seco (VM); and Villa Dolores Aero (VD)

the ENSO influence on rainfall and vegetation during the rainy season through the region.

The ENSO influence on the rainfall pattern over time was assessed by two time series: one between 1960 and 1999 $(n=40)$ and the other from 2000 to $2017(n=18)$. The latter also corresponds to the period with NDVI data used to verify the scope of the relationship between ENSO signal and rainfall. As the correlation for the entire 58-year period can be considered the reference value, those coefficients calculated for shorter periods were analyzed in terms of their membership with respect to the confidence interval of the long-term correlation $(p<0.05)$.

The confidence interval $(\mathrm{Cl})$ of correlation coefficient $(r)$ was calculated through the $\dot{Z}$ value that was obtained with the following expression [56]:

$\dot{Z}=\frac{1}{2} \operatorname{Ln} \frac{(1+r)}{(1-r)}$
Then, the lower limit of $\mathrm{Cl}\left(\mathrm{Cl}_{1}\right)$ with a $95 \%$ of probability $(p<0.05)$ was obtained as:

$\mathrm{Cl}_{l}=\operatorname{Tan} H\left(\dot{Z}-\frac{1.96}{\sqrt{n-3}}\right)$

and the upper limit of $\mathrm{Cl}\left(\mathrm{Cl}_{\mathrm{u}}\right)$ as:

$\mathrm{Cl}_{u}=\operatorname{Tan} H\left(\dot{Z}+\frac{1.96}{\sqrt{n-3}}\right)$

Three attributes of the rainfall regime were assessed in this study: the amount or total cumulative value (PP), the frequency of events or rainy days (DPP) and the maximum value of daily rainfall during the period (PPmax) [15]. The latter one is an indicator that has been used as a substitute to explore the rainfall intensity $[7,21,50]$.

The rainfall information of different localities was expressed in terms of the rainfall anomaly for the trimester or semester period ( $A X_{\text {period }}$ ) that, due to the long-term trend for some attributes, was calculated each year as the difference between the trimester October-November-December $\left(X_{\text {ond }}\right)$ or the semester October-November-December-January-February-March $\left(X_{\text {ondjfm }}\right)$, and the linear trend for each rainfall variable with respect to time $(T)$ from the initial to final year of the analyzed period, according to the following general expressions:

$A X_{\text {ond }}=X_{\text {ond }}-T_{\text {ond }}$

$A X_{\text {ondjfm }}=X_{\text {ondjfm }}-T_{\text {ondjfm }}$

where $X$ is either the total rainfall (PP), rainy days (DPP) or the maximum daily rainfall (PPmax) during the period and $T$ the linear trend about time.

\subsection{ENSO status: Southern Oscillation Index (SOI)}

The Southern Oscillation Index (SOI) was used here as a proxy to characterize the ENSO phenomenon $[14,17]$. The SOI represents the variation of atmospheric pressure on two opposite sectors in the Tropical Pacific Ocean, according to the following expression [8]:

$\mathrm{SOI}=10 \times\left[\frac{\mathrm{AP}_{\text {Tahiti }}-\mathrm{AP}_{\text {Darwin }}}{\mathrm{DEdif}}\right]$

where AP is the atmospheric pressure anomaly resulting from the difference between the monthly value and the long-term average (base period 1933-1992) at Tahiti and Darwin; DEdif is the standard deviation of the difference for the same base period. The SOI time series were obtained from the Australian Government-Bureau 
of Meteorology [4]. Following the Australian Bureau of Meteorology, sustained negative values of the SOI below -8 indicate $\mathrm{El} \mathrm{Niño} \mathrm{episode} \mathrm{and} \mathrm{positive} \mathrm{values} \mathrm{of} \mathrm{the}$ SOI above +8 are typical of a La Niña episode. SOI values between those limits are considered as Neutral cases.

Monthly SOI values were used as a rainfall predictor individually, and also they were aggregated from bimonthly, threemonthly, and so on to annual period (January and February, from January to March, from January to April, and so on). Then, discarding January SOI value, the process was repeated beginning from February. At last, the final integration was from September to December, to analyze the ENSO influence just before the rainy season begins in the study region.

To check for any change in the frequency of the ENSO phases during the period with radiometric information, the confidence intervals of El Niño, La Niña and Neutral status during the period of climatic character were calculated. The exact values of the bilateral, lower and upper confidence ends $\left(\pi_{1}, \pi_{\mathrm{u}}\right)$, which define the confidence interval $(\mathrm{Cl})$ of the relative frequency value $(\pi)$,

$\mathrm{Cl}: \pi_{l} \leq \pi \leq \pi_{u}$

can be calculated using [56]:

$\pi_{l}=\frac{x}{x+(n-x+1) F}$ with $F\left(d f_{1}=2(n-x+1), d f_{2}=2 x\right)$;

and

$\pi_{u}=\frac{(x+1) F}{n-x+(x+1) F} \quad$ with $\quad F\left(d f_{1}=2(x+1), d f_{2}=2(n-x)\right)$

where $x$ represents the number of cases under the established condition, $n$ is the size of the sample and $F$ the value of the Fisher's distribution with the respective degrees of freedom $(d f)$.

\subsection{ENSO Modoki status: ENSO Modoki Index (EMI)}

To characterize and assess the ENSO Modoki phenomenon, [2] proposed the El Niño Modoki Index (EMI) based on the sea surface temperature anomaly (SSTA) in different regions of the Pacific Ocean. While conventional El Niño is characterized by strong anomalous warming in the eastern equatorial Pacific, El Niño Modoki is associated with strong anomalous warming in the central tropical Pacific and cooling in the eastern and western tropical Pacific [51]. This particular SSTA pattern is different from what happens during typical EI Niño events. Because of the unique tripolar nature of the SSTA during El Niño Modoki, the index is defined as follows:

$\mathrm{EMI}=[\mathrm{SSTA}]_{A}-0.5 x[\mathrm{SSTA}]_{B}-0.5 x[\mathrm{SSTA}]_{C}$ where the brackets in Eq. (10) represent the area-averaged SSTA over each of the region $\mathrm{A}\left(165^{\circ} \mathrm{E}-140^{\circ} \mathrm{W}, 10^{\circ} \mathrm{S}-10^{\circ}\right.$ $\mathrm{N}), \mathrm{B}\left(110^{\circ} \mathrm{W}-70^{\circ} \mathrm{W}, 15^{\circ} \mathrm{S}-5^{\circ} \mathrm{N}\right)$ and $\mathrm{C}\left(125^{\circ} \mathrm{E}-145^{\circ} \mathrm{E}, 10^{\circ}\right.$ $\left.\mathrm{S}-20^{\circ} \mathrm{N}\right)$, respectively. Time series of EMI for this analysis were extracted from Japan Agency for Marine-Earth Science and Technology (Japan Agency for Marine-Earth Science and Technology [29]. Then, monthly EMI values were aggregated and analyzed exactly in the same way as SOI.

\subsection{Normalized difference vegetation index (NDVI) data}

Spectral vegetation indices have been developed to relate reflectance from leaves or canopies with vegetation characteristics and conditions [27]. The normalized difference vegetation index (NDVI) is the most frequently used vegetation index for developing vegetation cover estimation models [32]. The NDVI data were used as a proxy of vegetation in this study. Data of NDVI from MODIS-TERRA satellite, launched in 2000, with a $250 \mathrm{~m}$ spatial resolution, have both a good temporal coverage of 18 years by 2018 and an appropriate spatial detail.

The NDVI is a dimensionless index that expresses the presence and density of vegetation, calculated according to the following equation [27]:

$\mathrm{NDVI}=\frac{\rho_{\text {nir }}-\rho_{\mathrm{r}}}{\rho_{\text {nir }}+\rho_{\mathrm{r}}}$

where $\rho_{\mathrm{r}}$ and $\rho_{\text {nir }}$ are reflectance values corresponding to red and near-infrared wavelengths, respectively.

The product MOD13Q1 was used in this study, which is a composition of 16 days using the maximum composite value (MCV) algorithm. The spatial resolution is $250 \mathrm{~m}$, and the images are radiometric and geometrically corrected, and available for the entire series of 16-day images from July 2000 until July 2018 . Only 25 pixels of each site around to the meteorological station were extracted to analyze. In each place, those pixels that presented a correlation less than 0.75 with respect to the rest of the set were discarded, looking for preserving the spatial homogeneity of the information.

The NDVI data for Córdoba city (BO) were extracted to the north of the city, next to the Pajas Blancas (PB) airport, to avoid the influence of the big city. The 16-day NDVI values were averaged on a monthly basis to make them compatible with SOI data. The series was then depurated by removing every datum that showed anomalous values according to the immediately precedent and subsequent NDVI data. Very few data had to be excluded. Finally, the anomaly of NDVI $\left(A N D_{\text {period }}\right)$ was expressed as the difference of NDVI and the linear trend, for both the trimester ond and for the semester ondjfm, according to the following expressions:

$\mathrm{AND}_{\text {ond }}=\mathrm{NDVI}_{\text {ond }}-T_{\text {ond }}$ 
$\mathrm{AND}_{\text {ondjfm }}=\mathrm{NDVI}_{\text {ondjfm }}-T_{\text {ondjfm }}$

\section{Results and discussion}

\subsection{ENSO and ENSO Modoki influence on the rainfall regime in Córdoba}

Looking for a suitable indicator to predict the rainfall behavior from the ENSO signal, a necessary condition is that the relationship must hold a high, significant and stable correlation over time. However, other relevant aspects to consider are the timing of the signal relative to the onset of rains, their ability to describe the phenomenon in a comprehensive manner and the geographic scope that holds the relationship. For this purpose, Fig. 2 shows graphically the procedure used, looking for a suitable indicator to anticipate the rainfall characteristics at Córdoba Province. Moreover, as there is a growing recognition that there exist two different types of El Niño, it is likely that ENSO Modoki can provide greater capacity to explain rainfall variability in Córdoba, so the El Niño Modoki Index (EMI) was also used to explore its effects.

Given that the rainy season in the central region of Argentina is of a monsoonal type, with about $80 \%$ of the annual average rainfall recorded from October to March, Fig. 2 shows the correlation between SOI and the accumulated rainfall for the trimester from October to December, at the beginning of rainy season [12], and also for the full rainy semester. For this analysis, the SOI and EMI data were calculated for different periods: from each month individually to bimonthly sequences, three-monthly, etc., completing the annual period. The scanning was done in advance to the start of rains, first forward by adding the SOI or EMI information 1 month at a time, and then backward, discarding the posterior month while year progresses. Moreover, to capture the occurrence of the phenomenon in a comprehensive manner for all rainfall indicators, only those correlation values of a significant nature are presented for each lapse and place.

Although Villa Dolores (VD) shows less evidence of association with SOI in Fig. 2, it shares some similar features of precipitation regime with the rest of sites in Córdoba. Because the rainy season starts toward the end of the year in VD, it is likely that the October and November information will not be particularly useful there [12]. The SOI signal for places in eastern and central Córdoba more humid areas shows a consistent and widespread association, particularly for the total amount of rainfall and the frequency of events. The relationship is negative in character, but its intensity is moderate only, since for any variable and analyzed lapse the correlation reaches an upper limit of -0.54 (for APPmax ond $_{\text {in }} \mathrm{RC}$ ). Although the correlation coefficients are quite low, they are not very different from those [60] obtained when predicting the monsoon rains in India using more complex neural network models.

Assessing the temporal change of the correlation between the SOI of each particular month with the following seasonal precipitation, signal intensity increases as the rainy period approaches, reaching maximum values from August to October, depending on the site [14]. Considering monthly correlation values for $\mathrm{APP}_{\text {ondjm }}$ only, the maximum in Marcos Juárez (MJ), Villa de María Río Seco (VM) and Pilar (PI) occurs in August, in Córdoba (BO), Río Cuarto (RC) and Villa Dolores (VD) is over September and for Laboulaye (LB) it happens in October.

With predictive purposes, it is interesting that after October the correlation for November and December tends to be equal to or less than for the previous months, so that their inclusion does not contribute effectively to improve the prediction. This behavior is most noticeable by considering the chromatic representation of Fig. 2 . For all rainfall indexes, the signal intensity increases as the first months of the year are discarded and, on the other hand, November and December SOI data do not increase the correlation. Thereby, the inclusion of this information is not useful for the purpose of constructing a potential predictor. This temporal dependence about SOI is especially valuable for developing more accurate rainfall forecast models [1].

While the correlation between monthly SOI and EMI data for the whole period from January 1960 to December 2017 reaches a value of -0.452 (data not shown), showing some dependence inverse between both indices, when the analysis was repeated using EMI data instead of SOI, the ENSO Modoki signal did not improve the predictive capacity over rainfall behavior during the subsequent rainy season, as Table 1 shows. Not only the coefficients of correlation are equal or lower than those of SOI for almost all rainfall attributes, but in VD the relationships between EMI and precipitation have been completely missing. Also, rainfall intensity in LB shows a negative correlation, instead of positive as is expected for EMI in this region. The highest frequency and persistence of the El Niño Modoki signal in recent years $[36,71]$ have not influenced rainfall over the study region in a particular way, as Table 1 shows when the different periods are compared. For this reason, the information about the relationship between EMI and rainfall is not included onwards.

As shown in Fig. 2, although there are other alternatives to combine the SOI values that could marginally improve the signal somewhere and for some precipitation 

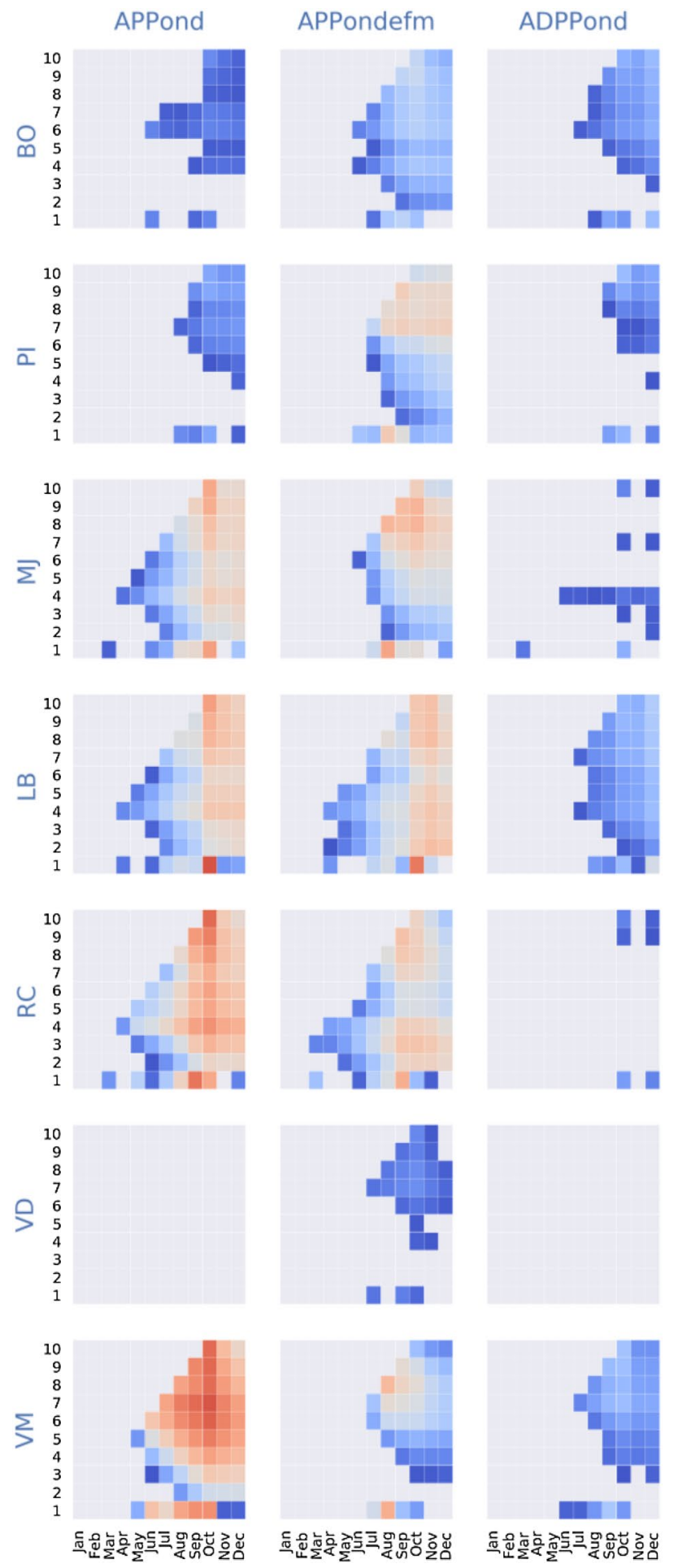

Fig. 2 Heat map representing color-coded levels of correlation coefficient between average of Southern Oscillation Index (SOI) ranging at different starting (in abscissa) and ending month (lag in ordinate), and the anomalies of total rainfall (PP), rainy days (DPP) and daily maximum precipitation (PPmax) for the trimester
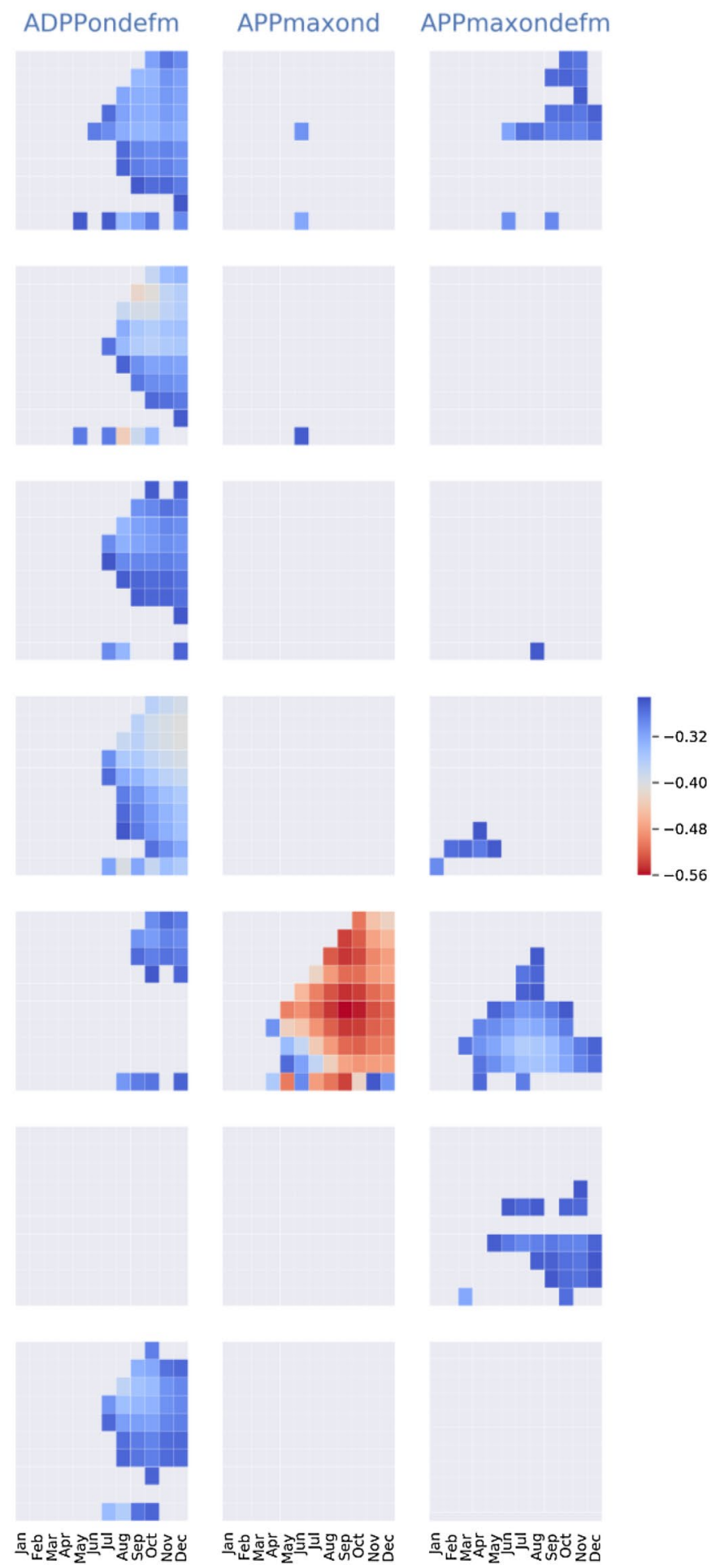

October-November-December (ond) and the semester OctoberNovember-December-January-February-March (ondjfm) during the period 1960-2017 in Córdoba, Argentina. Only the $r$ statistically significant $(p<0.05)$ is showed 
Table 1 Correlation coefficients between Southern Oscillation Index (SOI) (above) and El Niño Modoki Index (EMI) (below) of August-September (left) and July-August-September (right) with anomalies of total amount (APP), rainy days (ADPP) and maximum daily rainfall (APPmax) of October-November-December (ond) and semester October-November-December-January-FebruaryMarch (ondjfm) for different periods in Córdoba, Argentina

\begin{tabular}{|c|c|c|c|c|c|c|c|c|c|c|c|c|c|}
\hline & \multirow[t]{2}{*}{ Period } & \multicolumn{2}{|c|}{ APP } & \multicolumn{2}{|c|}{ ADPP } & \multicolumn{2}{|c|}{ APPmax } & \multicolumn{2}{|c|}{ APP } & \multicolumn{2}{|c|}{ ADPP } & \multicolumn{2}{|c|}{ APPmax } \\
\hline & & ond & ondjfm & ond & ondjfm & ond & ondjfm & ond & ondjfm & ond & ondjfm & ond & ondjfm \\
\hline & \multicolumn{7}{|c|}{$\mathrm{SOI}_{\mathrm{as}}$} & \multicolumn{6}{|c|}{$\mathrm{SOI}_{\mathrm{jas}}$} \\
\hline & 1960-1999 & -0.249 & -0.278 & -0.337 & -0.288 & -0.264 & -0.231 & -0.240 & -0.261 & -0.314 & -0.260 & -0.249 & -0.214 \\
\hline \multirow[t]{2}{*}{ BO } & 2000-2017 & -0.262 & -0.638 & -0.182 & -0.552 & -0.029 & -0.358 & -0.240 & -0.629 & -0.216 & -0.597 & 0.016 & -0.316 \\
\hline & 1960-2017 & -0.251 & -0.374 & -0.301 & -0.338 & -0.174 & -0.272 & -0.242 & -0.359 & -0.294 & -0.327 & -0.151 & -0.245 \\
\hline \multirow{3}{*}{ LB } & 1960-1999 & -0.521 & -0.383 & -0.355 & -0.333 & -0.147 & 0.100 & -0.508 & -0.408 & -0.304 & -0.301 & -0.173 & 0.097 \\
\hline & 2000-2017 & -0.182 & -0.386 & -0.213 & -0.450 & 0.209 & 0.357 & -0.221 & -0.385 & -0.308 & -0.512 & 0.217 & 0.401 \\
\hline & 1960-2017 & -0.398 & -0.377 & -0.310 & -0.369 & -0.006 & 0.153 & -0.406 & -0.394 & -0.306 & -0.369 & -0.021 & 0.156 \\
\hline \multirow{3}{*}{ MJ } & 1960-1999 & -0.459 & -0.486 & -0.305 & -0.339 & -0.275 & -0.171 & -0.433 & -0.473 & -0.270 & -0.318 & -0.278 & -0.160 \\
\hline & 2000-2017 & -0.340 & -0.370 & 0.068 & -0.233 & -0.062 & -0.256 & -0.351 & -0.399 & -0.020 & -0.312 & -0.001 & -0.223 \\
\hline & 1960-2017 & -0.428 & -0.453 & -0.204 & -0.302 & -0.214 & -0.192 & -0.414 & -0.452 & -0.206 & -0.314 & -0.201 & -0.174 \\
\hline \multirow{3}{*}{$\mathrm{PI}$} & 1960-1999 & -0.272 & -0.465 & -0.236 & -0.377 & -0.179 & -0.183 & -0.233 & -0.437 & -0.171 & -0.309 & -0.148 & -0.102 \\
\hline & 2000-2017 & -0.385 & -0.365 & -0.469 & -0.525 & -0.408 & -0.472 & -0.362 & -0.388 & -0.524 & -0.582 & -0.367 & -0.435 \\
\hline & 1960-2017 & -0.301 & -0.435 & -0.294 & -0.421 & -0.239 & -0.236 & -0.268 & -0.423 & -0.258 & -0.394 & -0.204 & -0.166 \\
\hline \multirow{3}{*}{$\mathrm{RC}$} & 1960-1999 & -0.537 & -0.522 & -0.181 & -0.226 & -0.650 & -0.356 & -0.512 & -0.508 & -0.153 & -0.186 & -0.654 & -0.372 \\
\hline & 2000-2017 & -0.322 & -0.293 & -0.357 & -0.462 & -0.236 & 0.137 & -0.301 & -0.292 & -0.373 & -0.453 & -0.214 & 0.072 \\
\hline & 1960-2017 & -0.483 & -0.447 & -0.228 & -0.305 & -0.539 & -0.206 & -0.463 & -0.441 & -0.211 & -0.273 & -0.544 & -0.243 \\
\hline \multirow{3}{*}{ VD } & 1960-1999 & -0.121 & -0.246 & 0.021 & -0.031 & -0.101 & -0.219 & -0.122 & -0.239 & 0.003 & -0.031 & -0.104 & -0.240 \\
\hline & 2000-2017 & 0.001 & -0.357 & -0.067 & -0.208 & -0.115 & -0.160 & -0.048 & -0.422 & -0.115 & -0.209 & -0.173 & -0.169 \\
\hline & 1960-2017 & -0.089 & -0.278 & -0.008 & -0.092 & -0.105 & -0.205 & -0.105 & -0.291 & -0.034 & -0.091 & -0.121 & -0.225 \\
\hline \multirow{4}{*}{ VM } & 1960-1999 & -0.564 & -0.447 & -0.339 & -0.332 & -0.228 & -0.264 & -0.537 & -0.437 & -0.293 & -0.316 & -0.242 & -0.268 \\
\hline & 2000-2017 & -0.290 & -0.350 & -0.352 & -0.321 & 0.063 & -0.153 & -0.353 & -0.409 & -0.458 & -0.432 & 0.093 & -0.196 \\
\hline & $1960-2017$ & -0.496 & -0.415 & -0.341 & -0.328 & -0.153 & -0.233 & -0.494 & & -0.331 & -0.347 & & -0.247 \\
\hline & \multicolumn{7}{|c|}{$\mathrm{EMI}_{\mathrm{as}}$} & \multicolumn{6}{|c|}{$\mathrm{EMI}_{\text {jas }}$} \\
\hline \multirow{3}{*}{ BO } & & 0.137 & 0.056 & 0.225 & -0.121 & 0.068 & 0.035 & 0.117 & 0.014 & 0.211 & -0.166 & 0.049 & 0.012 \\
\hline & 2000-2017 & 0.302 & 0.352 & 0.089 & 0.367 & 0.200 & 0.094 & 0.273 & 0.329 & 0.095 & 0.369 & 0.213 & 0.094 \\
\hline & $1960-2017$ & 0.156 & 0.113 & 0.183 & -0.049 & 0.100 & 0.052 & 0.137 & 0.075 & 0.179 & -0.085 & 0.091 & 0.036 \\
\hline & 1960-1999 & 0.177 & -0.175 & 0.031 & -0.065 & 0.234 & -0.394 & 0.137 & -0.232 & 0.017 & -0.095 & 0.242 & -0.411 \\
\hline LB & $2000-2017$ & 0.056 & 0.151 & 0.206 & 0.376 & -0.417 & -0.551 & 0.025 & 0.159 & 0.162 & 0.354 & -0.400 & -0.514 \\
\hline & $1960-2017$ & 0.124 & -0.085 & 0.069 & 0.063 & 0.001 & -0.433 & 0.092 & -0.121 & 0.047 & 0.032 & 0.021 & -0.435 \\
\hline & 1960-1999 & 0.426 & 0.208 & 0.231 & -0.072 & 0.317 & -0.222 & 0.385 & 0.149 & 0.236 & -0.106 & 0.282 & -0.264 \\
\hline MJ & 2000-2017 & 0.238 & 0.186 & 0.049 & & 0.121 & 0.253 & 0.195 & 0.151 & 0.070 & & 0.168 & 0.236 \\
\hline & $1960-2017$ & 0.371 & 0.202 & 0.172 & 0.042 & 0.264 & -0.116 & 0.335 & 0.149 & 0.186 & 0.014 & 0.251 & -0.159 \\
\hline & 1960-1999 & 0.115 & 0.048 & 0.172 & -0.074 & 0.028 & -0.030 & 0.086 & 0.011 & 0.170 & -0.104 & 0.013 & -0.055 \\
\hline PI & 2000-2017 & 0.310 & 0.324 & 0.247 & 0.372 & 0.262 & 0.535 & 0.300 & 0.317 & 0.223 & & 0.260 & 0.516 \\
\hline & $1960-2017$ & 0.146 & 0.111 & 0.176 & 0.041 & 0.080 & 0.052 & 0.123 & 0.080 & 0.172 & 0.021 & 0.065 & 0.027 \\
\hline & 1960-1999 & 0.282 & 0.142 & 0.161 & -0.006 & 0.480 & 0.185 & 0.257 & 0.093 & 0.161 & -0.040 & 0.449 & 0.137 \\
\hline $\mathrm{RC}$ & $2000-2017$ & 0.183 & 0.169 & 0.135 & 0.153 & 0.177 & -0.148 & 0.158 & 0.157 & 0.102 & 0.127 & 0.135 & -0.161 \\
\hline & $1960-2017$ & 0.247 & 0.137 & 0.154 & 0.044 & 0.384 & 0.078 & 0.227 & 0.101 & 0.147 & 0.011 & 0.361 & 0.048 \\
\hline & 1960-1999 & -0.053 & -0.096 & -0.007 & -0.090 & 0.134 & -0.092 & -0.078 & -0.114 & -0.009 & -0.111 & 0.098 & -0.099 \\
\hline VD & 2000-2017 & -0.216 & 0.105 & -0.183 & -0.125 & -0.095 & 0.157 & -0.212 & 0.122 & -0.154 & -0.115 & -0.124 & 0.162 \\
\hline & $1960-2017$ & -0.098 & -0.055 & -0.056 & -0.104 & 0.081 & -0.048 & -0.113 & -0.065 & -0.048 & -0.113 & 0.050 & -0.054 \\
\hline & 1960-1999 & 0.320 & 0.062 & -0.015 & -0.174 & 0.273 & 0.172 & 0.284 & 0.013 & -0.055 & -0.220 & 0.276 & 0.140 \\
\hline VM & 2000-2017 & 0.231 & 0.303 & 0.260 & 0.260 & -0.155 & 0.141 & 0.229 & 0.326 & 0.297 & 0.291 & -0.153 & 0.169 \\
\hline & $1960-2017$ & 0.293 & 0.124 & 0.030 & -0.084 & 0.176 & 0.166 & 0.267 & 0.093 & 0.005 & -0.114 & 0.184 & 0.148 \\
\hline
\end{tabular}

References: In red, bold and cursive the coefficients with statistical significance $(p<0.05)$; in green the coefficients are inside the confidence interval; in blue and orange the coefficients are outside the confidence interval

features in particular, a good predictor for all region can be set from the SOI values of July, August and September, looking for to anticipate the behavior of rainfall in the immediate subsequent season. The October information, which is also potentially valid, belongs to a period where rainfall is part of the estimate, and, as such, it is not considered appropriate to be included. Thus, the two indicators analyzed to predict the behavior of rain immediately subsequent are the $\mathrm{SOI}$ average for the trimester July-August-September and for the period of August-September. For comparative purposes, Table 1 shows the correlation between these ENSO signals with 
the different properties of rainfall regime evaluated, and it is included also those coefficients obtained from the ENSO Modoki signal to verify its worse performance.

Similarly, Chan et al. [5] showed that when the Indian Ocean Dipole (IOD) reaches its peak phase, the regional rainfall anomalies increase over subtropical La Plata Basin while they decrease over central Brazil, in austral spring. Also, they found that the associated lowlevel anomalous anticyclone next to the coast of Brazil increased the moisture flux and gives rise to the anomalously high precipitation over Uruguay and northern Argentina.

Table 1 displays the indifference of the SOI contribution in July for a predictive purpose. As was to be expected due to the high correlation between the two indicators $(r=0.979)$, no main differences are detected between them and, for that reason, only the August and September SOI average $\left(\mathrm{SOI}_{\mathrm{as}}\right)$ data are analyzed later on because of its greater simplicity and proximity to the start of the rainy cycle.

Except in some isolated cases, the ENSO signal affects inversely all those features used to represent the rainfall regime: quantity, frequency and intensity. Moreover, ENSO is also useful as a proxy to estimate the behavior of precipitation in the region of both the initial trimester of rainfall and the whole semester. Villafuerte et al. [67] also found that interannual variations in extreme precipitation indices are influenced greatly by the ENSO over Philippines. Thus, it is possible to project this information to describe every year the behavior of precipitation before the start of the rainy season in the region, which is suitable to both support the decision of seeding and anticipate the rainfall characteristics during summer crop season.

Also, $\mathrm{SOI}_{\mathrm{as}}$ presents a relatively stable behavior along time. According to Table 1, the signal intensity shows only little variations in the different periods considered. If the coefficient of correlation for the whole period 1960-2017 is considered as the climatic long-term behavior, then a confidence interval can be established. For most meteorological stations and rainfall attributes analyzed, the coefficients corresponding to the shorter periods (1960-1999 and 2000-2017) present values that are included in the respective confidence intervals, which suggests that the relationship has maintained some temporal stability. This result is of particular interest when the SOI-PP relationship is evaluated in the most recent period that includes the spectral information since, in spite of its small extension, it looks appropriate to represent the climatic behavior.

Contrary to [51], who found that the ENSO Modoki events significantly, and distinctly, affect seasonal rainfall in Africa, EMI does not show a superior predictive capacity than SOI in Córdoba territory. With correlations equal to or lesser than the SOI produced for each site and period, these results confirm that the ENSO Modoki signal does not improve the ENSO traditional signal to predict rainfall behavior in Córdoba.

\subsection{ENSO influence on the rainfall regime in Córdoba using SOI as proxy}

Having identified a reliable and appropriate predictor of the subsequent seasonal rainfall, the specific predictive capacity of this signal is now assessed using a linear regression analysis to establish how much interannual variability is able to explain. Figure 3 presents scatter plots between the average SOI of August and September immediately before the start of the rainy season and the amount of rain, the frequency of events and the maximum daily amount for the trimester (October-November-December) and semester (from October to March) subsequent in Córdoba, Argentina.

While dispersion is important, as indicated by the relatively low determination coefficients, negative linear relationships are established and geographically widespread throughout the territory. Except in VD, discarded for lack of statistical significance, and in LB when maximum daily rainfall is evaluated, this scheme is repeated throughout the region and for different features of rainfall. This scheme about the rainfall and $\mathrm{SOI}$ relationships is just contrary to the Indo-Pacific region $[44,67]$.

Making a comprehensive interpretation of all this information, when the intensity of ENSO signal increases (decreases) during La Niña (El Niño) events, it is likely that the rainfall anomaly in the trimester and semester subsequent takes progressively more negative (positive) values. Also, if only positive values of SOI during the cold phase are considered, we can expect that the decline in rainfall in the central region of Argentina would possibly be accompanied by a decrease in the frequency of cases, extending the periods between soil water recharge, as well as by a decrease in the intensity of the events, which may result in an incomplete refill of soil water content, all of which constitutes a negative combination that tends to aggravate an emerging drought condition. As was indicated by Rivera and Penalba [53], the ENSO information is useful for a seasonal rainfall prediction in South America and can be applied particularly to forecast droughts under La Niña conditions.

An easy way to implement alternatives to reduce the estimation error is to classify the SOl-averaged August-September $\left(\mathrm{SOI}_{\mathrm{as}}\right)$ in the three particular categories of the events: El Niño $\left(\mathrm{SOI}_{\mathrm{as}}<-8\right)$, La Niña $\left(\mathrm{SOI}_{\mathrm{as}}>8\right)$ and Neutral. This procedure produces results similar to those obtained using the monthly SOI values of the entire year for the categorization of the ENSO phases (Table 2). As shown in Fig. 4, although the statistical evaluation of Villa 
(a)

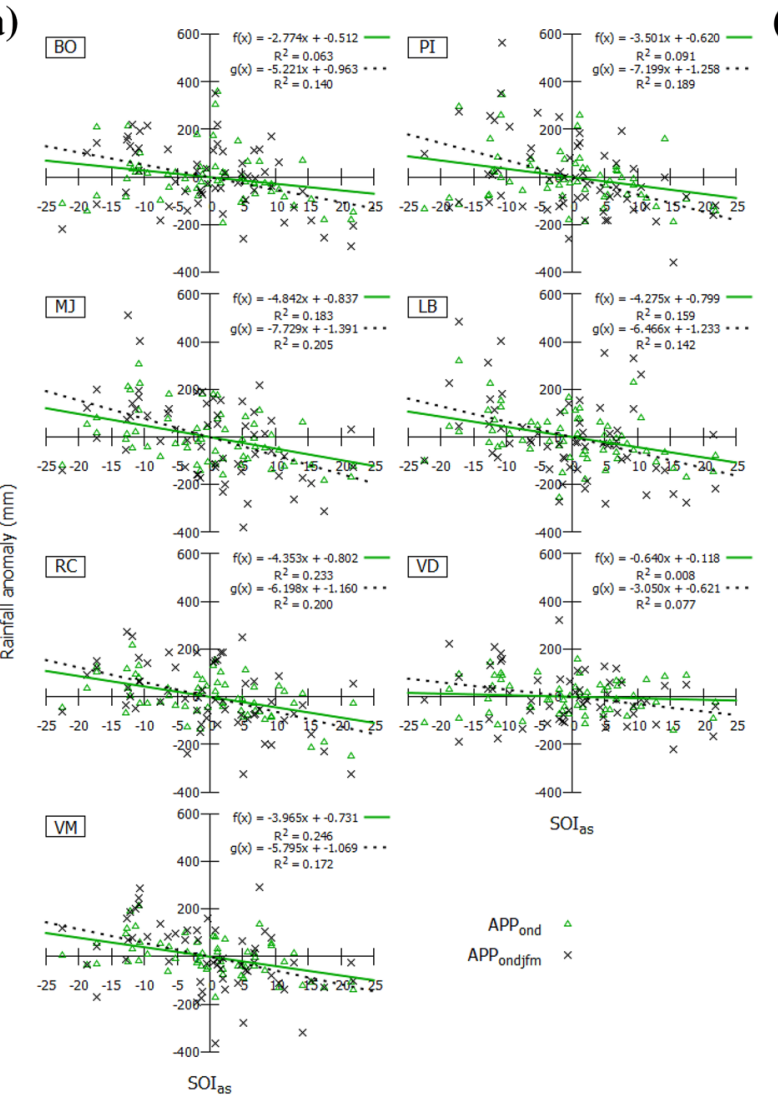

(b)

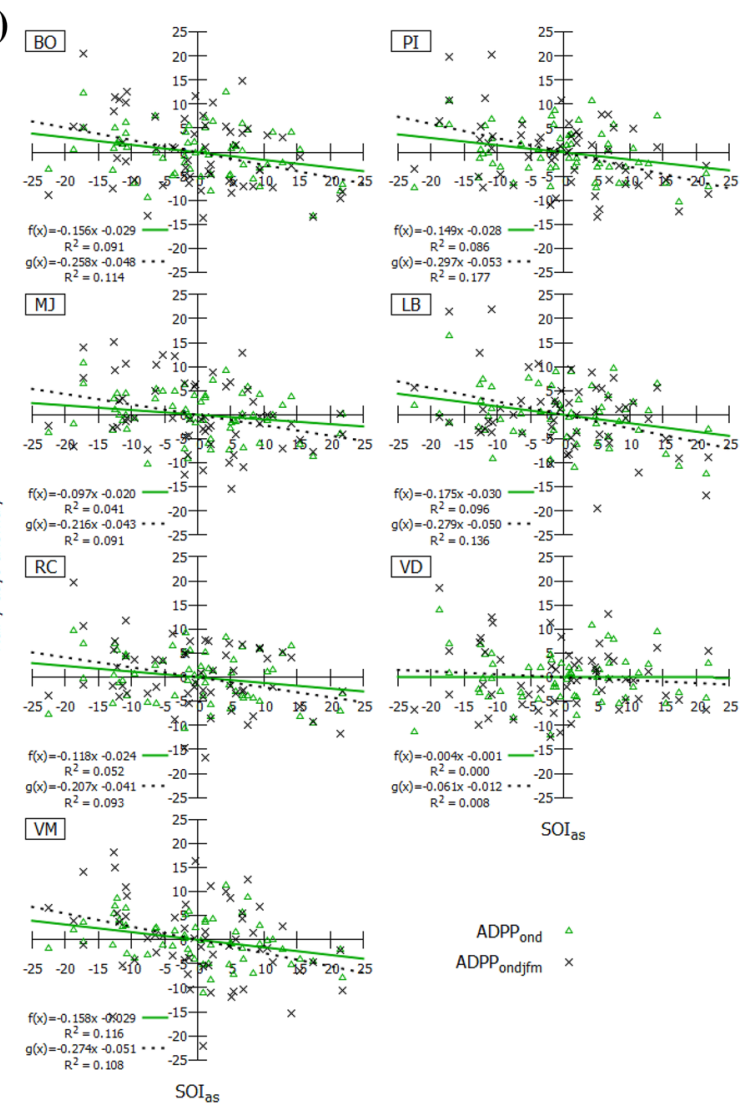

(c)

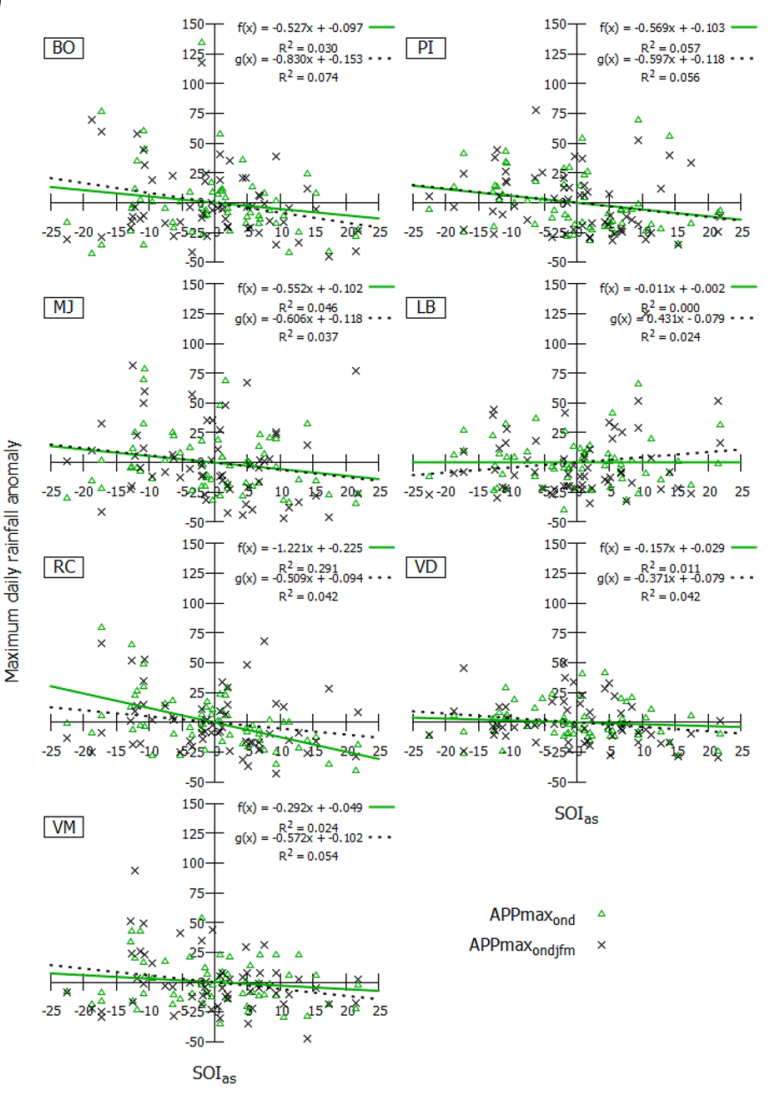


4 Fig. 3 a Scatter plot between Southern Oscillation Index of AugustSeptember $\left(\mathrm{SOl}_{\mathrm{as}}\right)$ and the anomaly of rain for trimester OctoberNovember-December ( APP $_{\text {ond }}$, green triangles) and semester October-November-December-January-February-March $\quad\left(\right.$ APP $_{\text {ondifm }}{ }^{\prime}$ black cross) subsequent in Córdoba since 1960-2017. $R^{2}>0.067$ is significant $(p<0.05)$. b Scatter plot between Southern Oscillation Index of August-September ( $\mathrm{SOI}_{\mathrm{as}}$ ) and the anomaly of rainy days for trimester October-November-December (ADPP ${ }_{\text {ond }}$ green triangles) and semester October-November-December-January-FebruaryMarch (ADPP ondjfm $^{\prime}$ black cross) subsequent in Córdoba since 1960 to 2017. $R^{2}>0.067$ is significant $(p<0.05)$. c Scatter plot between Southern Oscillation Index of August-September $\left(\mathrm{SOI}_{\mathrm{as}}\right)$ and the anomaly of maximum daily rainfall for trimester October-November-December (APPmax ${ }_{\text {ond }}$ green triangles) and semester October-November-December-January-February-March (APPmax ondjfm, black cross) subsequent in Córdoba since 1960 to $2017 . R^{2}>0.067$ is significant $(p<0.05)$

Dolores is not significant $(p<0.05)$, the determination coefficients of the linear relations between the SOI and precipitation increase systematically and almost duplicate when Neutral years are excluded. Concurrently, as the extraction of $57 \%$ of Neutral cases increases only slightly the slope, the linear relationship can be considered as stable because this filtering does not change its inclination. A higher predictive accuracy in terms of determination coefficient increase is repeated for the frequency of rainfall, though the $R^{2}$ values are mostly lower in this case.

\subsection{ENSO influence on vegetation using NDVI as proxy}

\subsubsection{ENSO phases' frequency in the analyzed period}

The NDVI MODIS information from the TERRA satellite, with data available from 2000, was analyzed until 2018. Despite this short period of data availability, the results represent satisfactorily the long-term correlation between rainfall and ENSO (Table 1). In the same way, since frequency of ENSO events in the period 1960-2017 allows to calculate its respective confidence intervals, it was established that the relative frequency values of the El Niño, La Niña and Neutral states for the most recent interval 2000-2017 are within the confidence interval of the expected long-term behavior. Table 2 presents the relative frequency results obtained, where in addition to the classification obtained for the different phases using $\mathrm{SOI}_{\mathrm{as}}$ as the index, the status of the phenomenon for the all calendar year was also considered, using the modal value of the 12 months classified according to each of the three ENSO categories as a criterion.

The results obtained from $\mathrm{SOI}_{\mathrm{as}}$, both in the long-term (58 years) and for the shorter and most recent period (18 years), are included inside the frequency interval of the annual classification in the period between 1960 and 2017. In addition, when using $\mathrm{SOI}_{\text {as }}$ a tendency is observed to increase the identification of El Niño and La Niña cases, to the detriment of the Neutral years. This confirms that the frequency values of El Niño, La Niña and Neutral events in the period with radiometric information not only are very similar to those of climatic character, but they are also within the confidence interval of the long-term relative frequency.

\subsubsection{Relationship between seasonal rainfall and NDVI}

Modulated by ENSO, atmospheric conditions influence the rainfall regime in Córdoba so that, when El Niño (La Niña) phase is presented, it is more likely an increase (decrease) in the amount of rainfall, the number of events and also their intensity. This periodic disturbance to a wetter or drier weather condition must necessarily have an impact on vegetation, whose status and dynamics can now be characterized from spectral indicators like NDVI $[3,23,30]$. Therefore, the NDVI variation configures evidence to verify the predictive capacity of the atmospheric and oceanic signal of ENSO from a more holistic perspective $[41,49]$.

As was established by [72], ENSO is globally the leading climatic driver of interannual variability of NDVI during the vegetation growing season, especially over southern and eastern Africa, eastern Australia, northeastern Asia and northern South America. However, although rainfall is closely linked to the vegetation growth, other environmental and productive factors can also modify the NDVI expression locally $[42,65]$. In order to evaluate this hypothesis, first a correlation and regression analysis between the PP and NDVI values during the warm semester is performed as shown in Fig. 5. Moreover, the seasonal analysis was extended so that accumulated rainfall and NDVI are also considered from October to April, October to May, November to March, November to April and November to May. Likewise, due to the delay that vegetation growth experiences with respect to rainfall occurrence, the seasonal analysis was carried out by lagging the NDVI accumulation in relation to the rainfall record $[31,68]$. Thus, the relationship between the PP and the NDVI was analyzed considering exactly the same time period ( $i$ ) for both variables, with a delay of the NDVI of 1 month $(i+1)$ and for a delay of the NDVI of 2 months $(i+2)$ with respect to the rainfall record (i).

Figure 5 a shows the relationship between the accumulated values of PP and NDVI during the warm semester, for NDVI values delayed by 1 month with respect to rainfall. The seasonal rainfall influence on the accumulated NDVI value was analyzed by a linear model, whose coefficients were obtained empirically by correlation and regression, both considering the complete set of information to represent regional behavior, and for each place in particular. 
Table 2 Relative frequency of events classified as La Niña, Neutral and El Niño using the SOI index for all calendar year ( $\mathrm{SOI}_{\text {year }}$ ) and for August-September $\left(\mathrm{SOI}_{\mathrm{as}}\right)$, with the confidence interval superior $(\mathrm{Cls})$ and inferior $(\mathrm{Cli})$ and the respective $\mathrm{F}$ values of $\mathrm{Cls}(\mathrm{Fs})$ and $\mathrm{Cli}$ (Fi) for the period 1960-2017

\begin{tabular}{|c|c|c|c|c|c|}
\hline & & \multicolumn{2}{|c|}{ 1960-2017 } & \multicolumn{2}{|c|}{$2000-2017$} \\
\hline & & $\mathrm{SOI}_{\text {year }}$ & $\mathrm{SOl}_{\mathrm{as}}$ & $\mathrm{SOI}_{\text {year }}$ & $\mathrm{SOI}_{\mathrm{as}}$ \\
\hline \multicolumn{6}{|c|}{ La Niña } \\
\hline Fs & 1.820 & & & & \\
\hline $\mathrm{Fi}$ & 2.172 & & & & \\
\hline Cls & 0.29 & 0.17 & 0.19 & 0.17 & 0.17 \\
\hline $\mathrm{Cli}$ & 0.09 & & & & \\
\hline \multicolumn{6}{|c|}{ Neutral } \\
\hline Fs & 1.767 & & & & \\
\hline $\mathrm{Fi}$ & 1.678 & & & & \\
\hline $\mathrm{Cls}$ & 0.78 & 0.66 & 0.57 & 0.78 & 0.61 \\
\hline $\mathrm{Cli}$ & 0.52 & & & & \\
\hline \multicolumn{6}{|c|}{ El Niño } \\
\hline Fs & 1.820 & & & & \\
\hline $\mathrm{Fi}$ & 2.172 & & & & \\
\hline $\mathrm{Cls}$ & 0.29 & 0.17 & 0.24 & 0.06 & 0.22 \\
\hline $\mathrm{Cli}$ & 0.09 & & & & \\
\hline
\end{tabular}

In addition, to take into account long-term changes in the variables, both rainfall and NDVI values were expressed as an anomaly with respect to the linear trend, as Fig. 5b shows. The assessment of the relationship between the anomaly of both rainfall and NDVI for other seasonal periods and the delay effect is presented in Table 3.

As Fig. 5a shows, dispersion is large for the region as a whole, with a coefficient of determination $\left(R^{2}\right)$ that, although very significant in statistical terms $(p<0.001)$, is relatively low (between 0.06 and 0.18 ), depending on the seasonal period and delay considered. However, an increase in seasonal rainfall has a positive effect on vegetation growth in the region as expected. When the linear relationship is established for values corrected by the trend in Fig. 5b, while the result of about 0.16 for the warm semester with 1-month lag in NDVI is very close to the value obtained for the variables without trend, for the other periods the $R^{2}$ in general is higher (between 0.11 and 0.28 ), validating the time trend influence over these variables.

Furthermore, when these variables were fitted by a polynomial of second degree, the $t$ values for the first- and second-degree terms are statistically significant and the $R^{2}$ results slightly higher also, which point out a certain nonlinear character of the relationship, with a tendency of the NDVI to decrease above a maximum rainfall record or, at least, not increasing. Using geographically weighted regression, [65] determined for Northern Nigeria that the relationship between NDVI and rainfall is clearly not linear.
The saturation behavior that NDVI signal presents in these relatively more humid environments was pointed out also by [49] for Africa, noting that the vegetation response to climate is complex and not completely known. Meanwhile, drought events that are represented by negative rainfall anomalies are translated into a progressive decline of biomass production (NDVI).

This general behavior has nuances and differences when each place is analyzed separately. This is difficult not only because of the climatic/environmental condition of each site, but also because of aspects linked to the particular agricultural management, from double cropped more intensively areas to sectors covered by natural vegetation or fallow. These contrasts are useful, however, to discriminate between different agricultural uses and land cover through the analysis of time series of NDVI $[18,69]$.

As shown in Fig. 5b, while PB, PI, VD and LB present linear relationships statistically significant $(p<0.05)$, with $R^{2}$ higher than for all the regions, in $\mathrm{MJ}, \mathrm{RC}$ and $\mathrm{VM}$, for its part, the relationship cannot sustain formally. Just to emphasize some aspects of interest, while the seasonal rainfall at $\mathrm{PB}$ is within the regional range values (between 400 and $1100 \mathrm{~mm}$ ), the radiometric information is notably lower than for the other sites. The land surrounding Cordoba airport (PB) is not cultivated so that the predominant vegetation (shrub and pasture) have NDVI values below those of cropped areas. In addition, the absence of agricultural activity confers to these radiometric data a character more directly linked to rainfall, reaching a $R^{2}$ significantly higher than the regional value and a statistically significant relationship in this area.

To the east of the region, the highest water availability throughout the year in MJ, even with the addition of water from underground layer, can explain the NDVI's independent behavior with respect to the warm season rainfall. Likewise, NDVI data of MJ in Fig. 5a reach the highest values in the region, indicating here the major productive capacity. On the other hand, VD is located in a relatively more arid sector to the west of the region, so that, with a lower rainfall range (between 400 and $800 \mathrm{~mm}$ ) and for a higher water atmospheric demand, vegetation shows more strong response to rainfall occurrence. The linear relationship is statistically significant for VD and has the highest angular coefficient, indicating that each $\mathrm{mm}$ of rainfall produces a greater NDVI increase.

\subsubsection{Relationship between seasonal NDVI and SOI}

The period with radiometric information analyzed between 2000 and 2017 not only preserves a correlation structure for the response of rainfall to ENSO which is similar to the long term, but also convincingly reproduces the 

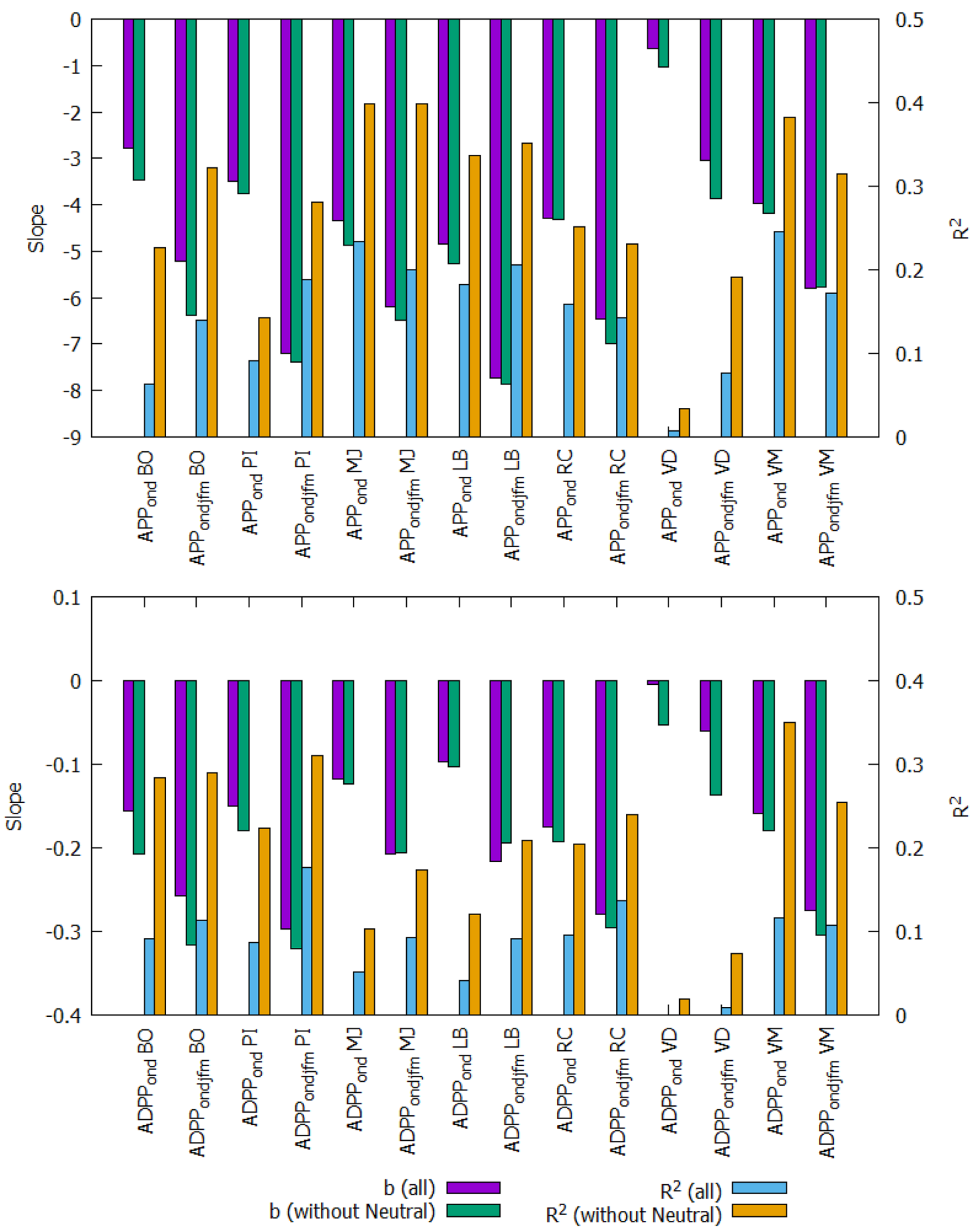

Fig. 4 Linear slope (b) and the coefficient of determination $\left(R^{2}\right)$ for the relationship between the SOI of August-September and total rainfall (above) and rainy days (below) for the trimester October-

relative frequency of the different ENSO phases that the phenomenon presents on a climatic scale. According to the linear relationships in Fig. 6 for the periods from October to March and from November to April, a configuration similar to the relationship between seasonal rainfall and
November-December and the warm semester in different sites of Córdoba, Argentina

ENSO is observed, with positive anomalies of NDVI during the El Niño events and negative ones during the opposite phase. This description is sustained in particular when the analysis involves the information as a whole (without discriminating between sites), although the $R^{2}$ is low and 

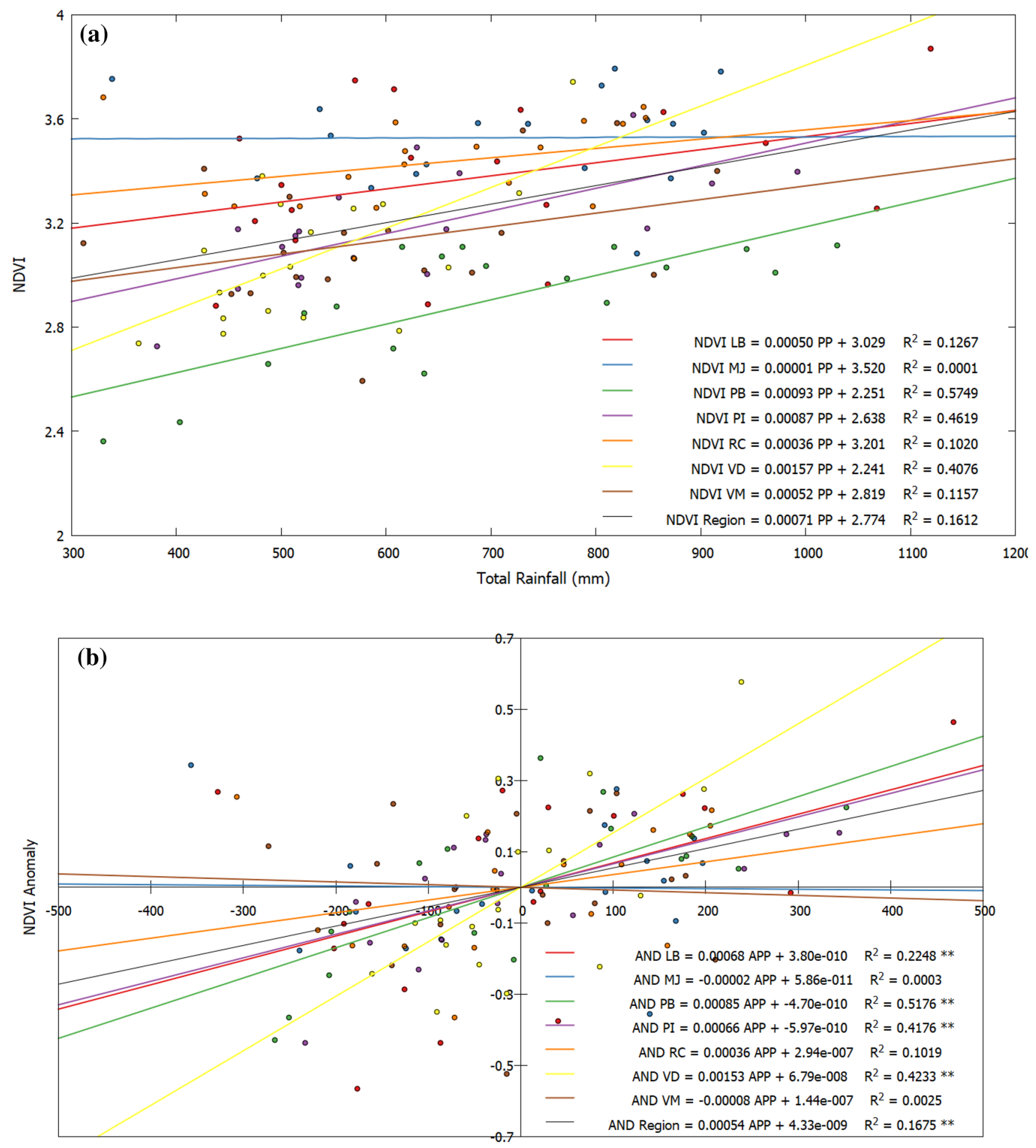

Total Rainfall Anomaly ( $\mathrm{mm}$ )

Fig. 5 a Scatter plot between accumulated values of rainfall between October and March and the NDVI with 1-month $(i+1)$ lag (from November to April) for the different sites in the period 2000-2017. In each place and for the entire region, the points were adjusted to straight lines whose regression and determination coefficients are presented also. $\mathbf{b}$ As above but for the anomaly of rainfall and NDVI [**statistically significant $(p<0.05)]$ 
Table 3 Coefficients of regression (a: intercept; b: slope) and determination $\left(R^{2}\right)$ for the linear relationship between seasonal rainfall anomaly and accumulated NDVI anomaly for different periods (i), and with 1-month $(i+1)$ and 2-month $(i+2)$ lag, for each site and the entire region. Also Fisher's $F$ statistic and its probability level

\begin{tabular}{|c|c|c|c|c|c|c|c|c|c|c|c|c|c|c|c|}
\hline \multirow[b]{2}{*}{ Region } & \multicolumn{3}{|c|}{ Oct-Mar } & \multicolumn{3}{|c|}{ Oct-Abr } & \multicolumn{3}{|c|}{ Oct-May } & \multicolumn{3}{|c|}{ Nov-Abr } & \multicolumn{3}{|c|}{ Nov-May } \\
\hline & $i$ & $i+1$ & $i+2$ & $i$ & $i+1$ & $i+2$ & $i$ & $i+1$ & $i+2$ & $i$ & $i+1$ & $i+2$ & $i$ & $i+1$ & $i+2$ \\
\hline b & 0.0005 & 0.0005 & 0.0005 & 0.0005 & 0.0006 & 0.0006 & 0.0006 & 0.0007 & 0.0008 & 0.0006 & 0.0006 & 0.0006 & 0.0007 & 0.0008 & 0.0009 \\
\hline$R^{2}$ & 0.113 & 0.167 & 0.112 & 0.135 & 0.181 & 0.176 & 0.141 & 0.227 & 0.245 & 0.197 & 0.178 & 0.195 & 0.197 & 0.239 & 0.278 \\
\hline$F$ & 15.867 & 24.944 & 15.674 & 19.310 & 27.410 & 26.473 & 20.303 & 36.387 & 40.342 & 30.407 & 26.806 & 30.055 & 30.432 & 38.984 & 47.774 \\
\hline $\mathrm{P}$ & 0.000 & 0.000 & 0.000 & 0.000 & 0.000 & 0.000 & 0.000 & 0.000 & 0.000 & 0.000 & 0.000 & 0.000 & 0.000 & 0.000 & 0.000 \\
\hline \multicolumn{16}{|l|}{$\angle B$} \\
\hline b & 0.0005 & 0.0007 & 0.0006 & 0.0006 & 0.0006 & 0.0006 & 0.0005 & 0.0006 & 0.0007 & 0.0007 & 0.0007 & 0.0009 & 0.0005 & 0.0007 & 0.0010 \\
\hline$R^{2}$ & 0.106 & 0.225 & 0.187 & 0.131 & 0.198 & 0.204 & 0.092 & 0.177 & 0.222 & 0.210 & 0.256 & 0.355 & 0.151 & 0.250 & 0.369 \\
\hline $\mathrm{F}$ & 1.906 & 4.641 & 3.679 & 2.409 & 3.952 & 4.102 & 1.618 & 3.440 & 4.563 & 4.250 & 5.511 & 8.793 & 2.840 & 5.335 & 9.372 \\
\hline $\mathrm{P}$ & 0.186 & 0.047 & 0.073 & 0.140 & 0.064 & 0.060 & 0.222 & 0.082 & 0.048 & 0.056 & 0.032 & 0.009 & 0.111 & 0.035 & 0.007 \\
\hline \multicolumn{16}{|l|}{ MJ } \\
\hline$b$ & -0.0001 & 0.0000 & -0.0002 & 0.0001 & 0.0000 & 0.0000 & 0.0002 & 0.0003 & 0.0003 & 0.0001 & -0.0001 & 0.0003 & 0.0002 & 0.0002 & 0.0006 \\
\hline$R^{2}$ & 0.007 & 0.000 & 0.048 & 0.007 & 0.001 & 0.000 & 0.015 & 0.037 & 0.056 & 0.004 & 0.004 & 0.038 & 0.024 & 0.032 & 0.152 \\
\hline $\mathrm{F}$ & 0.110 & 0.005 & 0.807 & 0.117 & 0.011 & 0.004 & 0.241 & 0.609 & 0.952 & 0.070 & 0.060 & 0.630 & 0.392 & 0.526 & 2.865 \\
\hline $\mathrm{P}$ & 0.744 & 0.944 & 0.382 & 0.737 & 0.918 & 0.951 & 0.630 & 0.447 & 0.344 & 0.795 & 0.809 & 0.439 & 0.540 & 0.479 & 0.110 \\
\hline \multicolumn{16}{|l|}{ PB } \\
\hline b & 0.0006 & 0.0008 & 0.0010 & 0.0007 & 0.0009 & 0.0010 & 0.0009 & 0.0011 & 0.0011 & 0.0008 & 0.0010 & 0.0009 & 0.0010 & 0.0011 & 0.0010 \\
\hline $\mathrm{R}^{2}$ & 0.339 & 0.518 & 0.582 & 0.420 & 0.607 & 0.603 & 0.502 & 0.621 & 0.622 & 0.583 & 0.648 & 0.618 & 0.630 & 0.657 & 0.634 \\
\hline $\mathrm{F}$ & 8.196 & 17.168 & 22.288 & 11.606 & 24.720 & 24.302 & 16.105 & 26.197 & 26.341 & 22.394 & 29.454 & 25.937 & 27.299 & 30.713 & 27.669 \\
\hline $\mathrm{P}$ & 0.011 & 0.001 & 0.000 & 0.004 & 0.000 & 0.000 & 0.001 & 0.000 & 0.000 & 0.000 & 0.000 & 0.000 & 0.000 & 0.000 & 0.000 \\
\hline \multicolumn{16}{|l|}{$P I$} \\
\hline b & 0.0007 & 0.0007 & 0.0006 & 0.0008 & 0.0008 & 0.0007 & 0.0009 & 0.0009 & 0.0008 & 0.0008 & 0.0008 & 0.0006 & 0.0009 & 0.0009 & 0.0007 \\
\hline$R^{2}$ & 0.344 & 0.418 & 0.339 & 0.414 & 0.485 & 0.433 & 0.415 & 0.468 & 0.379 & 0.502 & 0.548 & 0.365 & 0.487 & 0.549 & 0.341 \\
\hline $\mathrm{F}$ & 8.400 & 11.471 & 8.190 & 11.304 & 15.072 & 12.201 & 11.337 & 14.088 & 9.764 & 16.147 & 19.400 & 9.191 & 15.205 & 19.480 & 8.286 \\
\hline$P$ & 0.010 & 0.004 & 0.011 & 0.004 & 0.001 & 0.003 & 0.004 & 0.002 & 0.007 & 0.001 & 0.000 & 0.008 & 0.001 & 0.000 & 0.011 \\
\hline \multicolumn{16}{|l|}{$R C$} \\
\hline b & 0.0003 & 0.0004 & 0.0004 & 0.0001 & 0.0003 & 0.0004 & 0.0001 & 0.0004 & 0.0008 & 0.0004 & 0.0004 & 0.0002 & 0.0005 & 0.0006 & 0.0007 \\
\hline$R^{2}$ & 0.052 & 0.102 & 0.061 & 0.006 & 0.059 & 0.061 & 0.010 & 0.087 & 0.129 & 0.115 & 0.071 & 0.015 & 0.139 & 0.103 & 0.093 \\
\hline $\mathrm{F}$ & 0.871 & 1.815 & 1.039 & 0.092 & 1.003 & 1.035 & 0.163 & 1.518 & 2.372 & 2.085 & 1.228 & 0.241 & 2.582 & 1.836 & 1.634 \\
\hline $\mathrm{P}$ & 0.365 & 0.197 & 0.323 & 0.766 & 0.332 & 0.324 & 0.692 & 0.236 & 0.143 & 0.168 & 0.284 & 0.630 & 0.128 & 0.194 & 0.219 \\
\hline \multicolumn{16}{|l|}{$V D$} \\
\hline b & 0.0015 & 0.0015 & 0.0012 & 0.0015 & 0.0015 & 0.0013 & 0.0015 & 0.0017 & 0.0015 & 0.0016 & 0.0014 & 0.0012 & 0.0016 & 0.0016 & 0.0014 \\
\hline $\mathrm{R}^{2}$ & 0.347 & 0.423 & 0.347 & 0.367 & 0.433 & 0.398 & 0.338 & 0.437 & 0.443 & 0.430 & 0.492 & 0.353 & 0.400 & 0.492 & 0.400 \\
\hline $\mathrm{F}$ & 8.509 & 11.746 & 8.512 & 9.289 & 12.207 & 10.578 & 8.180 & 12.417 & 12.708 & 12.048 & 15.491 & 8.739 & 10.651 & 15.491 & 10.645 \\
\hline $\mathrm{P}$ & 0.010 & 0.003 & 0.010 & 0.008 & 0.003 & 0.005 & 0.011 & 0.003 & 0.003 & 0.003 & 0.001 & 0.009 & 0.005 & 0.001 & 0.005 \\
\hline \multicolumn{16}{|l|}{$V M$} \\
\hline b & 0.0005 & -0.0001 & -0.0003 & 0.0002 & 0.0001 & 0.0002 & 0.0003 & 0.0006 & 0.0009 & 0.0000 & -0.0001 & 0.0002 & 0.0002 & 0.0004 & 0.0008 \\
\hline$R^{2}$ & 0.071 & 0.003 & 0.024 & 0.010 & 0.003 & 0.009 & 0.025 & 0.081 & 0.140 & 0.001 & 0.005 & 0.017 & 0.010 & 0.033 & 0.163 \\
\hline $\mathrm{F}$ & 1.215 & 0.040 & 0.395 & 0.164 & 0.047 & 0.151 & 0.418 & 1.404 & 2.604 & 0.014 & 0.078 & 0.281 & 0.163 & 0.546 & 3.126 \\
\hline $\mathrm{P}$ & 0.287 & 0.843 & 0.538 & 0.691 & 0.831 & 0.702 & 0.527 & 0.253 & 0.126 & 0.906 & 0.783 & 0.603 & 0.692 & 0.471 & 0.096 \\
\hline
\end{tabular}

References: Coefficients in red (orange) with statistical significance $p<0.05(p<0.1)$ 

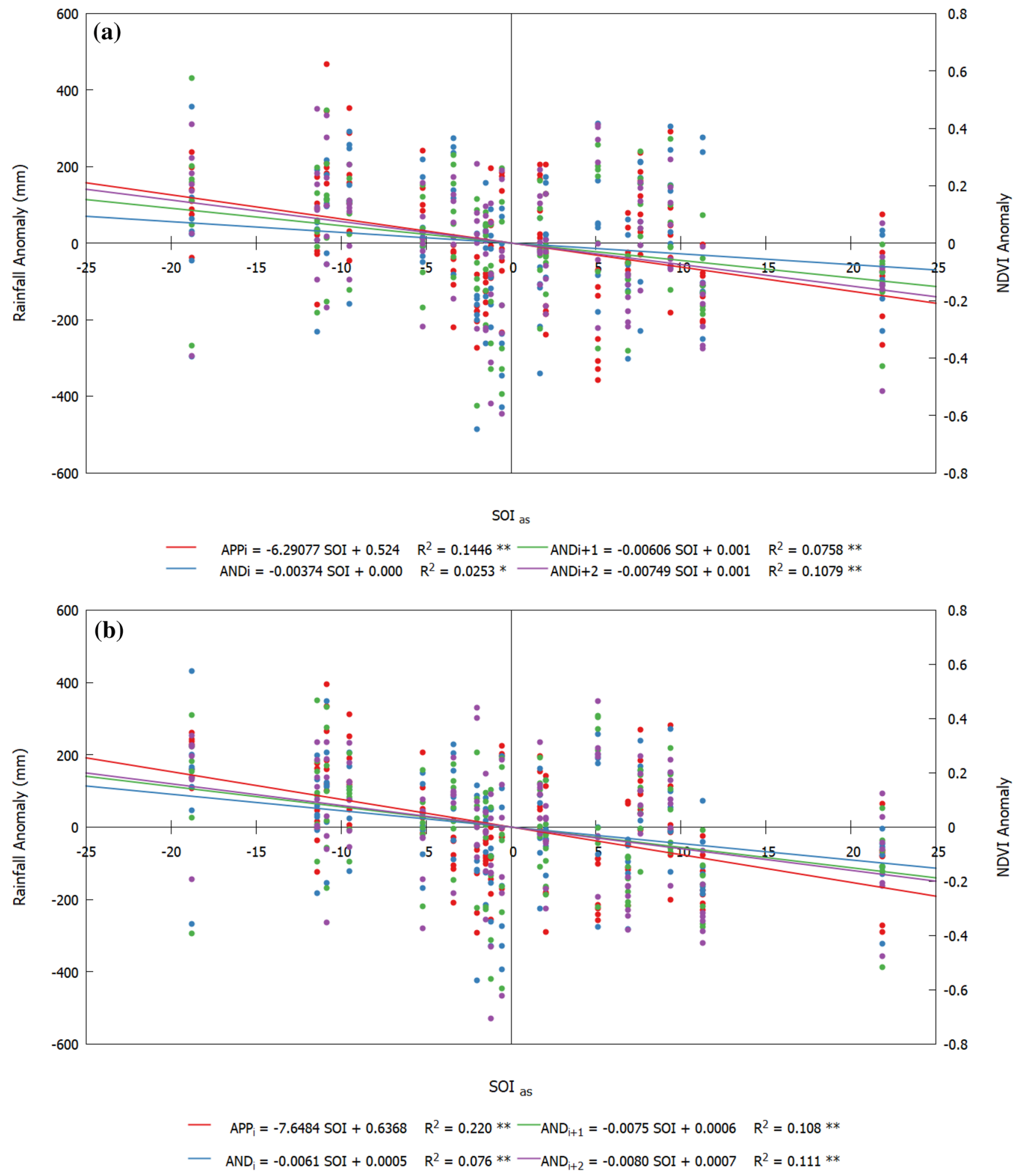

Fig. 6 Scatter plot between the Southern Oscillation Index of August-September $\left(\mathrm{SOI}_{\mathrm{as}}\right)$ and rainfall anomaly (APP) for the warm semester (a) and for the period from November to April (b), in Córdoba, Argentina. Also shown the relationship with NDVI anomaly
(AND) accumulated during the period (i) and with 1-month $(i+1)$ and 2-month $(i+2)$ lag ${ }^{* *}$ statistically significant $(p<0.05)$; * statistically significant $(p<0.10)]$ 
denotes a strong local influence. While in some places the relationship fits well, as in PB, in others this dependency does not exist at all, as in RC. Table 4 depicts the information for three periods from October to April, October to May and November to May, for the entire region and also each site. In addition, the association is strengthened when the radiometric information is delayed with respect to the rainfall record (from October to March), so that the accumulated NDVI values from November to April and even more between December and May show a more dependent relation with $\mathrm{SOI}_{\mathrm{as}}$.

Likewise, the delay effect in the response of vegetation is corroborated when other seasonal periods of accumulation are evaluated, which results in relationships even more correlated with $\mathrm{SOI}_{\mathrm{as}}$. In this sense, incorporating the radiometric information of April and May tends to increase the correlation, suggesting that the effective period of vegetation growth continues until after March. In the opposite direction, discarding the October information also increases the correlation and denotes that the seasonal growth of vegetation would start just after October.

Erasmi et al. [23] did not find significant correlations between NDVI and SOI in Indonesia when analyzing the relationship for the period from 1982 to 2006, but, using sea surface temperature (SST) as the ENSO index, the correlation was significant although very low. For the central region of Argentina, while the SOI cannot be discarded as a seasonal rainfall predictor, and to anticipate the vegetation behavior as well, the analysis of $\mathrm{SOI}_{\text {as }}$ predictive capacity for each particular site results in a more complex mosaic. The independence of the NDVI about the ENSO signal is verified for $\mathrm{MJ}$, which is consistent in some way because the warm semester (from October to March) rainfall does not have a significant influence here, as shown in Fig. 5. However, when other periods are considered in Table 4, as from November to April or to May, while the cumulative rainfall values show the inverse influence of the ENSO in a significant way, the NDVI values do not replicate this behavior at all.

In $\mathrm{PB}$, the $\mathrm{SOI}_{\mathrm{as}}$ is a consistent indicator to anticipate the behavior of both the seasonal rainfall and the NDVI; considering different seasonal periods and delay times, the predictive behavior is very generalized. Just in the center of the region, the predictive scheme for PI looks very similar to PB, but is less generalized. Even though rainfall information in Villa Dolores (VD) responds straight to the ENSO signal, this influence does not translate to the spectral information. This behavior is probably due to the fact that agriculture over there is carried out under irrigation.

During the period 2000-2017, the ENSO signal loses the predictive capacity in Río Cuarto, at least in statistical terms, for all seasonal lapses and delays considered. Nor does the relationship between the ENSO and the total rainfall amount reach statistical support, although it shows the negative trend expected for the entire region.

According to these results, it follows that while the ENSO phenomenon modulates short-term changes in the rainfall regime of Córdoba, Argentina, its effect is diluted a little when the impact is projected on the status and dynamics of vegetation. While the $\mathrm{SOI}_{\mathrm{as}}$ variation at regional scale can explain between 14 and $22 \%$ of annual variability of total rainfall for different seasonal periods, for accumulated NDVI values with 1 or 2 months of lag the range diminishes between 7 and $18 \%$ only. The evidence presented here suggests a consistent predictive relationship between the $\mathrm{SOI}_{\mathrm{as}}$ and the rainfall regime in the central region of Argentina, so that the ENSO indicator provides a valuable information in advance about the seasonal behavior of quantity, frequency and, to a lesser extent, intensity of rainfall, useful to mitigate both the environmental and agricultural risk.

When the relationship between the SOI and the accumulated NDVI is established instead, the same behavior is expressed roughly but reaching a lower degree of accuracy. Although the expected trend does not contradict (that is, an increase (decrease) in available water in El Niño (La Niña) years would produce the consequent increase (decrease) in biomass), other factors inherent to vegetation growth are not considered at all (initial biomass, previous soil moisture, soil type, temperature conditions, degradation, agricultural management, etc.) and thus restrict the scope of the radiometric information. Moreover, an apparent nonlinear nature of the relationship between NDVI and rainfall regime may also contribute to dilute this dependence, especially when 1-year El Niño occurs and the rainfall increase does not translate necessarily into more vegetation coverage or biomass.

\section{Conclusions}

The Southern Oscillation Index of August-September $\left(\mathrm{SOI}_{\mathrm{as}}\right)$ as a proxy of El Niño-Southern Oscillation (ENSO) is a signal linked with the rainfall regime in Córdoba, Argentina, both for the trimester from October to December and for the semester from October to March subsequent. The relationship is even more consistent when the accumulation period is after October and includes the months of April and May. Instead, the El Niño Modoki Index (EMI), used to represent the ENSO Modoki, showed lower correlation coefficients with the rainfall regime and did not improve the predictions about the subsequent rainfall behavior.

The relationships between $\mathrm{SOI}_{\mathrm{as}}$ and different attributes of rainfall regime are mostly linear and of inverse character. 
Table 4 Coefficients of regression (a: intercept; b: slope) and determination $\left(R^{2}\right)$ for the linear relationship between $\mathrm{SOl}_{\mathrm{as}}$ and seasonal rainfall (PP) and accumulated NDVI for different periods ( $(i)$ and with 1-month $(i+1)$ and 2 -month $(i+2)$ lag, for each site and the entire region. Also Fisher's F statistic and its probability level

\begin{tabular}{|c|c|c|c|c|c|c|c|c|c|c|c|c|}
\hline & \multicolumn{4}{|c|}{ Oct-Abr } & \multicolumn{4}{|c|}{ Oct-May } & \multicolumn{4}{|c|}{ Nov-May } \\
\hline & $\mathrm{PP} i$ & ND $i$ & ND $i+1$ & ND $i+2$ & $\mathrm{PP} i$ & ND $i$ & ND $i+1$ & ND $i+2$ & $\mathrm{PP} i$ & ND $i$ & ND $i+1$ & $\mathrm{ND} i+2$ \\
\hline \multicolumn{13}{|c|}{ Region } \\
\hline$a$ & 0.602 & 0.000 & 0.001 & 0.001 & 0.569 & 0.001 & 0.001 & 0.001 & 0.605 & 0.001 & 0.001 & 0.001 \\
\hline$b$ & -7.224 & -0.005 & -0.007 & -0.010 & -6.831 & -0.007 & -0.009 & -0.012 & -7.255 & -0.007 & -0.010 & -0.011 \\
\hline$R^{2}$ & 0.172 & 0.047 & 0.090 & 0.146 & 0.159 & 0.060 & 0.126 & 0.181 & 0.201 & 0.090 & 0.146 & 0.146 \\
\hline$F$ & 25.765 & 6.064 & 12.206 & 21.190 & 23.499 & 7.892 & 17.923 & 27.321 & 31.106 & 12.206 & 21.190 & 21.276 \\
\hline$P$ & 0.000 & 0.015 & 0.001 & 0.000 & 0.000 & 0.006 & 0.000 & 0.000 & 0.000 & 0.001 & 0.000 & 0.000 \\
\hline \multicolumn{13}{|l|}{$\angle B$} \\
\hline$a$ & 0.628 & 0.001 & 0.001 & 0.001 & 0.632 & 0.001 & 0.001 & 0.001 & 0.759 & 0.001 & 0.001 & 0.001 \\
\hline$b$ & -7.542 & -0.010 & -0.010 & -0.013 & -7.588 & -0.011 & -0.012 & -0.016 & -9.102 & -0.010 & -0.013 & -0.016 \\
\hline$R^{2}$ & 0.123 & 0.098 & 0.107 & 0.177 & 0.123 & 0.106 & 0.157 & 0.212 & 0.188 & 0.107 & 0.177 & 0.213 \\
\hline$F$ & 2.236 & 1.743 & 1.926 & 3.444 & 2.246 & 1.897 & 2.983 & 4.314 & 3.716 & 1.926 & 3.444 & 4.333 \\
\hline$P$ & 0.154 & 0.205 & 0.184 & 0.082 & 0.153 & 0.187 & 0.103 & 0.054 & 0.072 & 0.184 & 0.082 & 0.054 \\
\hline \multicolumn{13}{|c|}{$M J$} \\
\hline$a$ & 0.646 & 0.000 & 0.000 & 0.000 & 0.533 & 0.000 & 0.000 & 0.000 & 0.582 & 0.000 & 0.000 & 0.000 \\
\hline$b$ & -7.751 & -0.001 & -0.002 & 0.000 & -6.394 & -0.003 & -0.003 & -0.002 & -6.981 & -0.002 & 0.000 & -0.002 \\
\hline$R^{2}$ & 0.194 & 0.003 & 0.010 & 0.000 & 0.148 & 0.008 & 0.017 & 0.008 & 0.228 & 0.010 & 0.000 & 0.010 \\
\hline$F$ & 3.862 & 0.053 & 0.166 & 0.006 & 2.777 & 0.129 & 0.280 & 0.133 & 4.726 & 0.166 & 0.006 & 0.161 \\
\hline$P$ & 0.067 & 0.821 & 0.689 & 0.939 & 0.115 & 0.725 & 0.604 & 0.720 & 0.045 & 0.689 & 0.939 & 0.694 \\
\hline \multicolumn{13}{|l|}{$P B$} \\
\hline$a$ & 0.965 & 0.001 & 0.001 & 0.002 & 0.936 & 0.001 & 0.002 & 0.002 & 0.944 & 0.001 & 0.002 & 0.002 \\
\hline$b$ & -11.576 & -0.012 & -0.016 & -0.021 & -11.237 & -0.015 & -0.020 & -0.022 & -11.326 & -0.016 & -0.021 & -0.019 \\
\hline$R^{2}$ & 0.278 & 0.265 & 0.403 & 0.533 & 0.269 & 0.320 & 0.447 & 0.529 & 0.317 & 0.403 & 0.533 & 0.523 \\
\hline$F$ & 6.168 & 5.757 & 10.816 & 18.250 & 5.881 & 7.540 & 12.958 & 18.003 & 7.413 & 10.816 & 18.250 & 17.514 \\
\hline$P$ & 0.024 & 0.029 & 0.005 & 0.001 & 0.028 & 0.014 & 0.002 & 0.001 & 0.015 & 0.005 & 0.001 & 0.001 \\
\hline \multicolumn{13}{|l|}{$P I$} \\
\hline$a$ & 0.619 & 0.000 & 0.001 & 0.001 & 0.588 & 0.001 & 0.001 & 0.001 & 0.631 & 0.001 & 0.001 & 0.001 \\
\hline$b$ & -7.428 & -0.005 & -0.008 & -0.010 & -7.061 & -0.006 & -0.010 & -0.012 & -7.571 & -0.008 & -0.010 & -0.009 \\
\hline$R^{2}$ & 0.183 & 0.050 & 0.160 & 0.275 & 0.175 & 0.078 & 0.209 & 0.276 & 0.248 & 0.160 & 0.275 & 0.194 \\
\hline$F$ & 3.585 & 0.839 & 3.041 & 6.081 & 3.390 & 1.352 & 4.230 & 6.092 & 5.270 & 3.041 & 6.081 & 3.854 \\
\hline$P$ & 0.077 & 0.373 & 0.100 & 0.025 & 0.084 & 0.262 & 0.056 & 0.025 & 0.036 & 0.100 & 0.025 & 0.067 \\
\hline \multicolumn{13}{|l|}{$R C$} \\
\hline$a$ & 0.406 & 0.000 & 0.000 & 0.001 & 0.396 & 0.000 & 0.001 & 0.001 & 0.362 & 0.000 & 0.001 & 0.001 \\
\hline$b$ & -4.877 & -0.001 & -0.005 & -0.006 & -4.753 & -0.002 & -0.006 & -0.010 & -4.348 & -0.005 & -0.006 & -0.008 \\
\hline$R^{2}$ & 0.107 & 0.001 & 0.069 & 0.062 & 0.108 & 0.013 & 0.101 & 0.110 & 0.096 & 0.069 & 0.062 & 0.069 \\
\hline$F$ & 1.926 & 0.022 & 1.194 & 1.050 & 1.930 & 0.217 & 1.794 & 1.969 & 1.701 & 1.194 & 1.050 & 1.193 \\
\hline$P$ & 0.184 & 0.885 & 0.291 & 0.321 & 0.184 & 0.647 & 0.199 & 0.180 & 0.211 & 0.291 & 0.321 & 0.291 \\
\hline \multicolumn{13}{|l|}{$V D$} \\
\hline$a$ & 0.432 & 0.000 & 0.000 & 0.001 & 0.416 & 0.000 & 0.001 & 0.001 & 0.434 & 0.000 & 0.001 & 0.001 \\
\hline$b$ & -5.188 & -0.003 & -0.006 & -0.008 & -4.990 & -0.003 & -0.007 & -0.009 & -5.212 & -0.006 & -0.008 & -0.009 \\
\hline$R^{2}$ & 0.204 & 0.009 & 0.047 & 0.126 & 0.214 & 0.011 & 0.059 & 0.146 & 0.249 & 0.047 & 0.126 & 0.151 \\
\hline$F$ & 4.113 & 0.146 & 0.786 & 2.303 & 4.368 & 0.170 & 0.996 & 2.733 & 5.317 & 0.786 & 2.303 & 2.851 \\
\hline$P$ & 0.060 & 0.707 & 0.389 & 0.149 & 0.053 & 0.686 & 0.333 & 0.118 & 0.035 & 0.389 & 0.149 & 0.111 \\
\hline \multicolumn{13}{|c|}{$V M$} \\
\hline$a$ & 0.517 & 0.000 & 0.000 & 0.001 & 0.483 & 0.001 & 0.001 & 0.001 & 0.520 & 0.000 & 0.001 & 0.001 \\
\hline$b$ & -6.206 & -0.006 & -0.004 & -0.010 & -5.792 & -0.006 & -0.008 & -0.015 & -6.243 & -0.004 & -0.010 & -0.011 \\
\hline$R^{2}$ & 0.179 & 0.063 & 0.026 & 0.106 & 0.149 & 0.047 & 0.075 & 0.179 & 0.161 & 0.026 & 0.106 & 0.119 \\
\hline$F$ & 3.500 & 1.070 & 0.431 & 1.905 & 2.805 & 0.784 & 1.306 & 3.482 & 3.078 & 0.431 & 1.905 & 2.169 \\
\hline$P$ & 0.080 & 0.316 & 0.521 & 0.186 & 0.113 & 0.389 & 0.270 & 0.080 & 0.098 & 0.521 & 0.186 & 0.160 \\
\hline
\end{tabular}


Table 4 (continued)

References: Coefficients in red (orange) with statistical significance $p<0.05(p<0.1)$

When a phase La Niña (El Niño) occurs, positive (negative) values of $\mathrm{SOI}_{\text {as }}$ depict negative (positive) anomalies of rain that involve lower (higher) amount, frequency and intensity of the events. For both the trimester and the semester subsequent, rainfall estimates increase their accuracy when the Neutral years are discarded from the analysis.

Both the correlation structure between the rainfall regime and the ENSO in the region and the frequency of ENSO events for the period 2000-2017 are appropriate to represent the long-term climate behavior. The relationship between the $\mathrm{SOI}_{\mathrm{as}}$ and NDVI maintains a configuration which is similar to the ENSO influence over rainfall, and, despite the fact that some loss of accuracy was determined in this case, the NDVI information as a proxy of the vegetation presents an adequate capacity to highlight the influence of ENSO, particularly at a regional scale. For a local scale instead, the relationship of the ENSO with the NDVI has a more confusing interpretation as many environmental and agricultural management factors interact on the growth of vegetation.

Thus, while this information would help to reduce the uncertainty of interannual rainfall variability, as well as to enhance the early warning system on food and agriculture in the region [43], only a small part of the total variability can be explained from the ENSO signal (between 10 and $20 \%$ of total). Finally, the radiometric information of NDVI verifies very closely the influence the ENSO exerts on the rainfall regime, at least when the entire region is considered. While the spatial and temporal extent of influence of SOI and MEI on rainfall and NDVI was identified in this study, the teleconnection mechanisms between $\mathrm{SOI}$ and MEI with other climate drivers should be the subject of further research.

Acknowledgements This work was supported by the Secretaría de Ciencia y Técnica de la Universidad Nacional de Córdoba (SeCyT-UNC) [Grant Number 33620180100318CB].

\section{Compliance with ethical standards}

Conflict of interest The authors declare that they have no conflict of interest.

\section{References}

1. Abbot J, Marohasy J (2014) Input selection and optimization for monthly rainfall forecasting in Queensland, Australia, using artificial neural networks. Atmos Res 138:166-178
2. Ashok K, Behera SK, Rao SA, Weng H, Yamagata T (2007) El Niño Modoki and its possible teleconnection. J Geophys Res 112:C11007. https://doi.org/10.1029/2006JC003798

3. Baldi G, Nosetto MD, Aragón R, Aversa F, Paruelo JM, Jobbágy EG (2008) Long-term satellite NDVI data sets: evaluating their ability to detect ecosystem functional changes in South America. Sensors 8:5397-5425

4. Bureau of Meteorology-Australian Government, 2015. Information from http://www.bom.gov.au/climate/current/soiht m1.shtml

5. Chan SC, Behera SK, Yamagata T (2008) Indian Ocean Dipole influence on South American rainfall. Geophys Res Lett 35:L14S12. https://doi.org/10.1029/2008GL034204

6. Chang J, Hansen MC, Pittman K, Carroll M, DiMiceli C (2007) Corn and soybean mapping in the United States using MODIS time-series data sets. Agron J 99:1654-1664

7. Cislaghi M, De Michele C, Ghezzi A, Rosso R (2005) Statistical assessment of trends and oscillations in rainfall dynamics: analysis of long daily Italian series. Atmos Res 77:188-202

8. Chowdhury RK, Beecham S (2010) Australian rainfall trends and their relation to the Southern Oscillation Index. Hydrol Process 24:504-514

9. Chowdhury RK, Beecham S (2013) Influence of SOI, DMI and Niño 3.4 on South Australian rainfall. Stoch Environ Res Risk Assess 27:1909-1920

10. Compagnucci RH, Agosta EA (2008) La precipitación de verano en el centro-oeste de Argentina y los fenómenos interanual El Niño/Oscilación Sur (ENOS) e interdecádico "tipo" ENOS. Geoacta 33:97-103

11. Dai A, Wigley TML (2000) Global patterns of ENSO-induced precipitation. Geophys Res Lett 27(9):1283-1286

12. de la Casa A (2009) Onset of the rainy season in the province of Córdoba (Argentina) determined by rainfall records and evaluation of its agricultural risk condition. Chil J Agric Res 69(4):567-576

13. de la Casa AC, Nasello OB (2010) Breakpoints in annual rainfall trends in Córdoba, Argentina. Atmos Res 95:419-427

14. de la Casa AC, Nasello OB (2011) Capacidad predictiva del Niño-Oscilación Sur (ENSO) y de otros indicadores climáticos sobre la precipitación en Córdoba, Argentina. Anal AFA 22:114-119

15. de la Casa AC, Nasello OB (2012) Tendencias parciales de los días de lluvia y la intensidad media anual en la provincia de Córdoba, Argentina. Meteorológica 37(2):67-77

16. de la Casa AC, Nasello OB (2014) Análisis periódico de las condiciones hidrológicas en la Provincia de Córdoba, Argentina. Actas $99^{\circ}$ Reunión Nacional de Física de la Asociación Física Argentina. 22 al 25 de septiembre de 2014. Tandil, Buenos Aires, Argentina

17. de la Casa AC, Ovando GG (2006) Influencia de episodios El NiñoOscilación Sur (ENOS) sobre la precipitación y el rendimiento de maíz en la provincia de Córdoba, Argentina. Agric Téc (Chile) 66:80-89

18. de la Casa A, Ovando G (2007) Caracterización de la dinámica anual del uso del suelo en sistemas de producción agropecuarios de Córdoba, Argentina, por medio del análisis armónico en series de tiempo de NDVI. Revista de la Facultad de Agronomía, La Plata 106(2):155-164

19. de la Casa AC, Ovando GG (2014) Climate change and its impact on agricultural potential in the central region of Argentina between 1941 and 2010. Agric For Meteorol 195-196:1-11 
20. de la Casa AC, Ovando GG, Díaz GJ (2018) Secular variation of rainfall regime in the central region of Argentina. Atmos Res 213:196-210

21. de la Casa AC, Ovando GG, Nasello OB (2018) Changes in the intensity and variability of precipitation in the central region of Argentina between 1960 and 2012. Climate 6:66

22. Defries RS, Hansen MC, Townshend JRG, Janetos AC, Loveland TR (2000) A new global 1-km dataset of percentage tree cover derived from remote sensing. Glob Change Biol 6:247-254

23. Erasmi E, Propastin P, Kappas M (2009) Spatial patterns of NDVI variation over Indonesia and their relationship to ENSO warm events during the period 1982-2006. J Clim 22:6612-6623

24. Ferreyra RA, Podestá GP, Messina CD, Letson D, Dardanelli J, Guevara $E$, Meira S (2001) A linked-modeling framework to estimate maize production risk associated with ENSO-related climate variability in Argentina. Agric For Meteorol 107:177-192

25. Friedl MA, Mclver DK, Hodges JCF, Zhang XY, Muchoney D, Strahler AH, Woodcock CE, Gopal S, Schneider A, Cooper A, Baccini A, Gao F, Schaaf C (2002) Global land cover mapping from MODIS: algorithms and early results. Remote Sens Environ 83:287-302

26. Greene AM, Goddard L, Cousin R (2011) Web tool deconstructs variability in twentieth-century climate. EOS Trans AGU 92(45):397-398

27. Hatfield JL, Gitelson AA, Schepers JS, Walthall CL (2008) Application of spectral remote sensing for agronomic decisions. Agron J 100:S117-S131

28. Irmak S, Kabenge I, Skaggs KE, Mutiibwa D (2012) Trend and magnitude of changes in climate variables and reference evapotranspiration over 116-yr period in the Platte River Basin, central Nebraska-USA. J Hydrol 420-421:228-244

29. Japan Agency for Marine-Earth Science and Technology (JAMSTEC) (2016). Information from http://www.jamstec.go.jp/frcgc /research/d1/iod/enmodoki_home_s.html.en. Accessed 10 Oct 2018

30. Ji L, Peters AJ (2003) Assessing vegetation response to drought in the Northern Great Plains using vegetation and drought indices. Remote Sens Environ 87:85-98

31. Ji L, Peters AJ (2005) Lag and seasonality considerations in evaluating AVHRR NDVI response to precipitation. Photogram Eng Remote Sens 71(9):1053-1061

32. Jia $\mathrm{K}$, Liang $S, \mathrm{Gu} X$, Baret $F$, Wei $X$, Wang $X$, Yao $Y$, Yang L, Li $Y(2016)$ Fractional vegetation cover estimation algorithm for Chinese GF-1 wide field view data. Remote Sens Environ 177:184-191

33. Jiayou $H$ (2000) The response of climatic jump in summer in north China to global warming. Adv Atm Sci 17(2):184-192

34. Kao H-Y, Yu J-Y (2009) Contrasting eastern-Pacific and central-Pacific types of ENSO. J Clim 22:615-632. https://doi. org/10.1175/2008JCLI2309.1.2009

35. Kenyon J, Hegerl GC (2010) Influence of modes of climate variability on global precipitation extremes. J Clim 23:6248-6262. https://doi.org/10.1175/2010JCLI3617.1

36. Kim ST, Yu J-Y (2012) The two types of ENSO in CMIP5 models. Geophys Res Lett 39:L11704. https://doi.org/10.1029/2012G L052006

37. Kogan FN (2000) Satellite-observed sensitivity of world land ecosystems to El Niño/La Niña. Remote Sens Environ 74:445-462

38. Kug J-S, Jin F-F, An S-I (2009) Two types of El Niño events: Cold Tongue El Niño and Warm Pool El Niño. J Clim 22:1499-1515. https://doi.org/10.1175/2008JCLI2624.1

39. Kumar A, Hoerling MP (2003) The nature and causes for the delayed atmospheric response to El Niño. J Clim 16:1391-1403

40. Larkin NK, Harrison DE (2005) On the definition of El Niño and associated seasonal average U.S. weather anomalies. Geophys Res Lett 32:L13705. https://doi.org/10.1029/2005gl022738
41. Li Z, Kafatos M (2000) Interannual variability of vegetation in the United States and its relation to El Niño/Southern Oscillation. Remote Sens Environ 71(3):239-247

42. Li Z, Huffman T, McConkey B, Townley-Smith L (2013) Monitoring and modeling spatial and temporal patterns of grassland dynamics using time-series MODIS NDVI with climate and stocking data. Remote Sens Environ 138:232-244

43. Li Y, Strapasson A, Rojas O (2019) Assessment of El Niño/La Niña impacts on China: enhancing the early warning system on food and agriculture. Weather Clim Extremes. https://doi. org/10.1016/j.wace.2019.100208

44. Limsakul A, Singhruck $P$ (2016) Long-term trends and variability of total and extreme precipitation in Thailand. Atmos Res 169:301-317

45. Lucero OA, Rozas D (2002) Characteristics of aggregation of daily rainfall in a middle-latitudes region during a climate variability in annual rainfall amount. Atmos Res 61:35-48

46. Malone RW, Meek DW, Hatfield JL, Mann ME, Jaquis RJ, Ma L (2009) Quasi-biennial corn yield cycles in lowa. Agric For Meteorol 149:1087-1094

47. Minetti JL, Vargas WM (1998) Trends and jumps in the annual precipitation in South America, south of $15^{\circ} \mathrm{S}$. Atmósfera 11(4):205-221

48. Paruelo JM (2008) La caracterización funcional de ecosistemas mediante sensores remotos. Ecosistemas 17(3):4-22

49. Philippon N, Martiny N, Camberlin P, Hoffman MT, Gond V (2014) Timing and patterns of the ENSO signal in Africa over the last 30 years: insights from Normalized Difference Vegetation Index data. J Clim 27(7):2509-2532

50. Porto de Carvalho JR, Assad ED, Fortes de Oliveira A, Silveira Pinto $\mathrm{H}$ (2014) Annual maximum daily rainfall trends in the Midwest, southeast and southern Brazil in the last 71 years. Weather and Climate Extremes 5-6:7-15

51. Preethi B, Sabin TP, Adedoyin JA, Ashok K (2015) Impacts of the ENSO Modoki and other tropical Indo-Pacific climate-drivers on African rainfall. Sci Rep 5:16653. https://doi.org/10.1038/srep1 6653

52. Ríos-Cornejo D, Penas Á, Álvarez-Esteban R, del Río S (2015) Links between teleconnection patterns and precipitation in Spain. Atmos Res 156:14-28

53. Rivera JA, Penalba OC (2015) El Niño/La Niña events as a tool for regional drought monitoring in Southern South America. Drought: research and science-policy interfacingAndreu et al (Eds) 2015 Taylor \& Francis Group, London, ISBN 978-1-138-02779-4

54. Ropelewsky CF, Halpert MS (1987) Global and regional scale precipitation patterns associated with El Niño/Southern Oscillation. Mon Weather Rev 115(2):1606-1626

55. Rusticucci M, Vargas W (2002) Cold and warm events over Argentina and their relationship with the ENSO phases: risk evaluation analysis. Int J Climatol 22:467-483. https://doi.org/10.1002/ joc.743

56. Sachs L (1978) Estadística aplicada. Ed. Labor S.A., Barcelona

57. Scafetta N (2010) Empirical evidence for a celestial origin of the climate oscillations and its implications. J Atmos Solar Terr Phys 72:951-970

58. Seiler RA, Kogan F (2002) Monitoring ENSO cycles and their impacts on crops in Argentina from NOAA-AVHRR satellite data. Adv Space Res 30:2489-2493

59. Seiler R, Kogan F, Wei G, Vinocur M (2007) Seasonal and interannual responses of the vegetation and production of crops in Córdoba-Argentina assessed by AVHRR derived vegetation indices. Adv Space Res 39(1):88-94

60. Shukla RP, Tripathi KC, Pandey AC, Das IML (2011) Prediction of Indian summer monsoon rainfall using Niño indices: a neural network approach. Atmos Res 102:99-109 
61. Tomé AR, Miranda PMA (2004) Piecewise linear fitting and trend changing points of climate parameters. Geophys Res Lett 31:L02207. https://doi.org/10.1029/2003GL019100

62. Trenberth KE, Branstator GW, Karoly D, Kumar A, Lau N-C, Ropelewski $C$ (1998) Progress during TOGA in understanding and modeling global teleconnections associated with tropical sea surface temperatures. J Geophys Res 103:14291-14324

63. Trenberth KE, Stepaniak DP (2001) Indices of El Niño evolution. J Clim 14:1697-1701

64. Tularam GA (2010) Relationship between El Niño Southern Oscillation Index and rainfall (Queensland, Autralia). Int J Sustain Dev Plan 5(4):378-391

65. Usman U, Yelwa SA, Gulumbe SU, Danbaba A (2013) Modelling relationship between NDVI and climatic variables using geographically weighted regression. J Math Sci Appl 1(2):24-28. https://doi.org/10.12691/jmsa-1-2-2

66. van Leeuwen WJD, Hartfield K, Miranda M, Meza FJ (2013) Trends and ENSO/AAO driven variability in NDVI derived productivity and phenology alongside the Andes Mountains. Remote Sens 5:1177-1203

67. Villafuerte $M Q$, Matsumoto J, Akasaka I, Takahashi HG, Kubota $\mathrm{H}$, Cinco TA (2014) Long-term trends and variability of rainfall extremes in the Philippines. Atmos Res 137:1-13
68. Wang J, Rich PM, Price KP (2003) Temporal responses of NDVI to precipitation and temperature in the central Great Plains, USA. Int J Remote Sens 24(11):2345-2364

69. Wardlow BD, Egbert SL (2008) Large-area crop mapping using time-series MODIS $250 \mathrm{~m}$ NDVI data: An assessment for the U.S. Central Great Plains. Remote Sens Environ 112(3):1096-1116

70. Yao J, Chen Y (2015) Trend analysis of temperature and precipitation in the Syr Darya Basin in Central Asia. Theor Appl Climatol 120:521-531

71. Yu J-Y, Zou Y-H, Kim S-T, Lee T (2012) The changing impact of El Niño on US winter temperatures. Geophys Res Lett 39:L15702. https://doi.org/10.1029/2012GL052483

72. Zhao L, Dai A, Dong B (2018) Changes in global vegetation activity and its driving factors during 1982-2013. Agric For Meteorol 249:198-209

Publisher's Note Springer Nature remains neutral with regard to jurisdictional claims in published maps and institutional affiliations. 